\title{
Thiocyanate Anchors for Salt-like Iron(II) Complexes on Au(111): Promises and Caveats
}

\author{
Philipp Stock ${ }^{\mathrm{a}, \mathrm{b}}$, Andreas Erbe ${ }^{\mathrm{b}}$, Manfred Buck ${ }^{\mathrm{c}}$, Dennis Wiedemann ${ }^{\mathrm{a}}$, Hervé Ménard ${ }^{\mathrm{d}}$, \\ Gerald Hörner ${ }^{\mathrm{a}}$, and Andreas Grohmann ${ }^{\mathrm{a}}$ \\ ${ }^{a}$ Institut für Chemie, Sekr. C2, Technische Universität Berlin, Straße des 17. Juni 135, 10623 \\ Berlin, Germany \\ ${ }^{\mathrm{b}}$ Department of Interface Chemistry and Surface Engineering, Max-Planck-Institut für \\ Eisenforschung GmbH, Max-Planck-Straße 1, 40237 Düsseldorf, Germany \\ c EaStCHEM School of Chemistry, University of St Andrews, St Andrews KY16 9ST, United \\ Kingdom \\ d Sasol Technology (UK) Ltd, Purdie Building, North Haugh, St Andrews, KY16 9ST, United \\ Kingdom
}

Reprint requests to Professor Andreas Grohmann. Fax: +49-30 31479656.

E-mail: andreas.grohmann@tu-berlin.de

Z. Naturforsch. 2014, 69b, 1164 - 1180 / DOI: 10.5560/ZNB.2014-4159

Received July 15, 2014

Dedicated to Professor Hubert Schmidbaur on the occasion of his $80^{\text {th }}$ birthday

The formation of self-assembled monolayers (SAMs) on $\mathrm{Au}(111)$ from solution has been investigated for two ionic iron(II) complexes of the type $[\mathrm{Fe}(\mathrm{L})]\left(\mathrm{BF}_{4}\right)_{2}$, where $\mathrm{L}$ is tripodal hexadentate and contains three thiocyanate anchor groups. The ligands (L1, L2; donor set: $\mathrm{N}_{6}$ ) are obtained by Schiff base condensation of a tripodal triamine (L1: tris-(2-aminoethyl)amine, 'tren'; L2: 1,1',1' trimethyl(thiophosphoryl)trihydrazide) with 5-(4-thiocyanatobutoxy) pyridine-2-carbaldehyde. Layers of the complexes adsorbed on $\mathrm{Au}(111)$ from methanol solution have been characterised using scanning tunnelling microscopy (STM), infrared reflectance absorbance (IRRAS), X-ray photoelectron (XPS) and UV/Vis reflectance spectroscopies, as well as ellipsometry. Complex [Fe(L1)](BF 4$)_{2}$ deposits intact on a gold surface and retains its optical addressability. Elaboration of this result may provide access to a new class of self-assembled layers, employing salt-like tripodal coordination compounds with thiocyanate anchors. The second complex, $[\mathrm{Fe}(\mathrm{L} 2)]\left(\mathrm{BF}_{4}\right)_{2}$, which contains a sulphur atom in the ligand backbone, is not sufficiently stable under the same conditions.

Key words: Responsive Surfaces, Au(111), Iron(II), Nitrogen Ligands, Magnetic Properties

\section{Introduction}

Immobilisation of functional molecules on metal substrates is a key issue of contemporary materials science, in the context of creating responsive surfaces. A prototypical example is the formation of selfassembled monolayers (SAMs) using specialised organic molecules [1-4]. SAMs allow the quick and targeted functionalisation of surfaces and are interesting for many research areas, including sensor fabrication, molecular electronics, or corrosion protection $[2,5]$. Recent years have seen an improved understanding of surface structures, as well as more complex functionalities $[3,6,7]$. SAM formation involves organic molecules having a substrate-specific anchor group, a spacer group (typically an alkyl chain) and a 'head group', which is responsible for the characteristic properties imparted to the SAM [1]. By far the most popular substrate for SAM formation has been gold, and the most widely used anchoring group for such surfaces has been the thiol function. The high affinity of thiols towards gold results in generally high chemical stability of the adsorbate [1]. For SAMs to be well-ordered, however, it is advantageous to work with organic molecules that are relatively 'slender'. Bulging head groups are accommodated best if they can enter into lateral interactions, such as $\pi-\pi$ stacking [8]. A complementary approach 
to accommodate bulging head groups employs voluminous anchor groups [9], sometimes with multiple surface-binding functions [10]. The coating of (near)spherical gold nanoparticles, whose curved surface alleviates the 'space problem' caused by bulging head groups, with suitably functionalised transition metal complexes, has recently been reviewed [11]. It should be noted, however, that high crystallinity in SAMs is not, in itself, a prerequisite for surface functionality, and less well-ordered adsorbates could still be useful for modulating surface qualities. This having been said, the integration of organometallic or coordination compounds into SAMs is particularly worthwhile, as such units carry desirable redox, magnetic, or spectroscopic addressability.

A potential high-impact application of metal complex-containing SAMs is data storage at the molecular level. This might be realised using surfaceanchored bistable compounds, which would be switchable by an external stimulus [12]. Spin crossover (SCO) compounds are particularly promising here. In these, octahedrally coordinated transition metal ions with electron configurations $3 d^{4}-3 d^{7}$ undergo a reversible change between their high- and low-spin states in response to a change in temperature, pressure or illumination [13]. The possibility of optical stimulation using the LIESST effect (light-induced excited spin state trapping) [14] is very attractive in surfaceanchored 2D assemblies as it would, in principle, enable lateral resolution. Complexes of iron(II) are the most widely researched in the SCO context, both in the bulk and on surfaces [15-17]. Spin crossover was shown in a vacuum-deposited, physisorbed submonolayer of molecular (i.e., electrically neutral) iron(II) complexes in contact with highly oriented pyrolytic graphite [18] and on a gold surface [19], respectively. Such behaviour differs from previously found results, where the presence of a metal surface had been shown to suppress spin crossover in a substance in direct contact, or where only molecules in an ad-layer showed spin crossover [20-22]. Clearly, a better understanding of the behaviour of such compounds on a metallic surface is required, before iron(II) complexes can be used in molecular electronics in a predictable way. Uncharged metal complexes can sometimes be unsuitable for vacuum deposition [23]. Charged, salt-like complexes cannot generally be deposited by sublimation owing to low vapour pressures; if sublimation is attempted, decomposition and con- comitant fragment-induced surface contamination usually result. A less forcing strategy implies adsorption from solution. Here, reliable protocols for the immobilisation of metal complexes need to be developed; specifically, conditions need to be identified that allow monolayer formation from salt-like iron(II) complexes.

The present work explores a small island in what still is largely uncharted territory, namely the requirements a salt-like iron(II) complex must meet to be adsorbed onto $\mathrm{Au}(111)$ from solution, while maintaining its 'function'. For the latter, we are using the optical addressability of a complex, via its intense metal-to-ligand charge transfer absorption in the visible regime; this has the added benefit of simultaneously reporting on the magnetic state of the complex ion. In this context, we have synthesised and characterised two new iron(II) complexes, using the wellestablished $C_{3}$-symmetrical tripodal $\mathrm{N}_{6}$ ligand topology. Tripodal arrangements have been shown before to support stable surface architectures, and SAMs of complex molecules have been successfully prepared using space-demanding tripodal anchors [24-27]. While thiol groups have been most widely used to attach metal complexes to a gold surface [28, 29], some workers have also used thioesters [30-32], thioethers [27, 33, 34] or, prior to us, thiocyanates [35]. These 'masked' S-containing functional groups, while retaining a high affinity for gold, are far less reactive towards the central ion in the complex. In the present work, we have adapted the thiocyanate (RSCN) approach [36-39] and studied the deposition on $\mathrm{Au}(111)$ of two tripodal iron(II) complexes, by what we intended to be 'three-point interactions' using flexible alkyl spacers (Scheme 1). Structure and nature of the adsorbates were characterised by means of scanning tunnelling microscopy (STM), ellipsometry, X-ray photoelectron spectroscopy (XPS), IRRAS, and

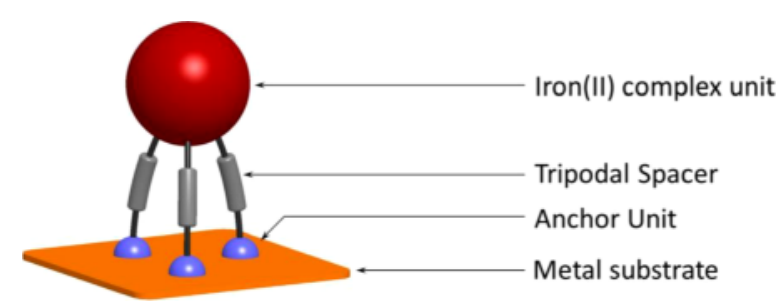

Scheme 1 (colour online). Sketch of a surface-anchored tripodal complex. 
$\mathrm{UV} /$ Vis reflectance spectroscopy. We have found one set of conditions which preserve the optical properties of the pristine complex. XPS data of an adsorbed layer are compatible with complex stoichiometry, indicating that the coordination unit remains intact throughout the assembly process.

\section{Results and Discussion}

\section{Target substances and their characterisation}

Ligand building blocks ('head groups') with threefold symmetry and functional groups amenable to ready derivatisation are central to the present study. Inspired by previous work on $\mathrm{N}_{3} \mathrm{~N}_{3}$ podands, we chose two such head groups. One is $1,1^{\prime}, 1^{\prime \prime}$-trimethyl(thiophosphoryl)trihydrazide (5) [40, $41]$, and the other tris-(2-aminoethyl)amine (tren, 4) $[42,43]$, Scheme 2. Either head group has three primary amino functions allowing for straightforward and high-yielding derivatisation by Schiff base condensation with a suitable pyridine-derived aldehyde, thereby creating the targeted $\mathrm{N}_{6}$ donor set. It is noted that ligand 5 carries an additional sulphur atom in an exposed position. As it turned out during the surfacegrafting studies (vide infra), the thiophosphoryl unit is labile on $\mathrm{Au}(111)$. The synthesis of the target complexes $\mathbf{6}^{\mathbf{F e}}$ and $\mathbf{7}$ is summarised in Scheme 2 (a similar protocol was used for the synthesis of the anal-
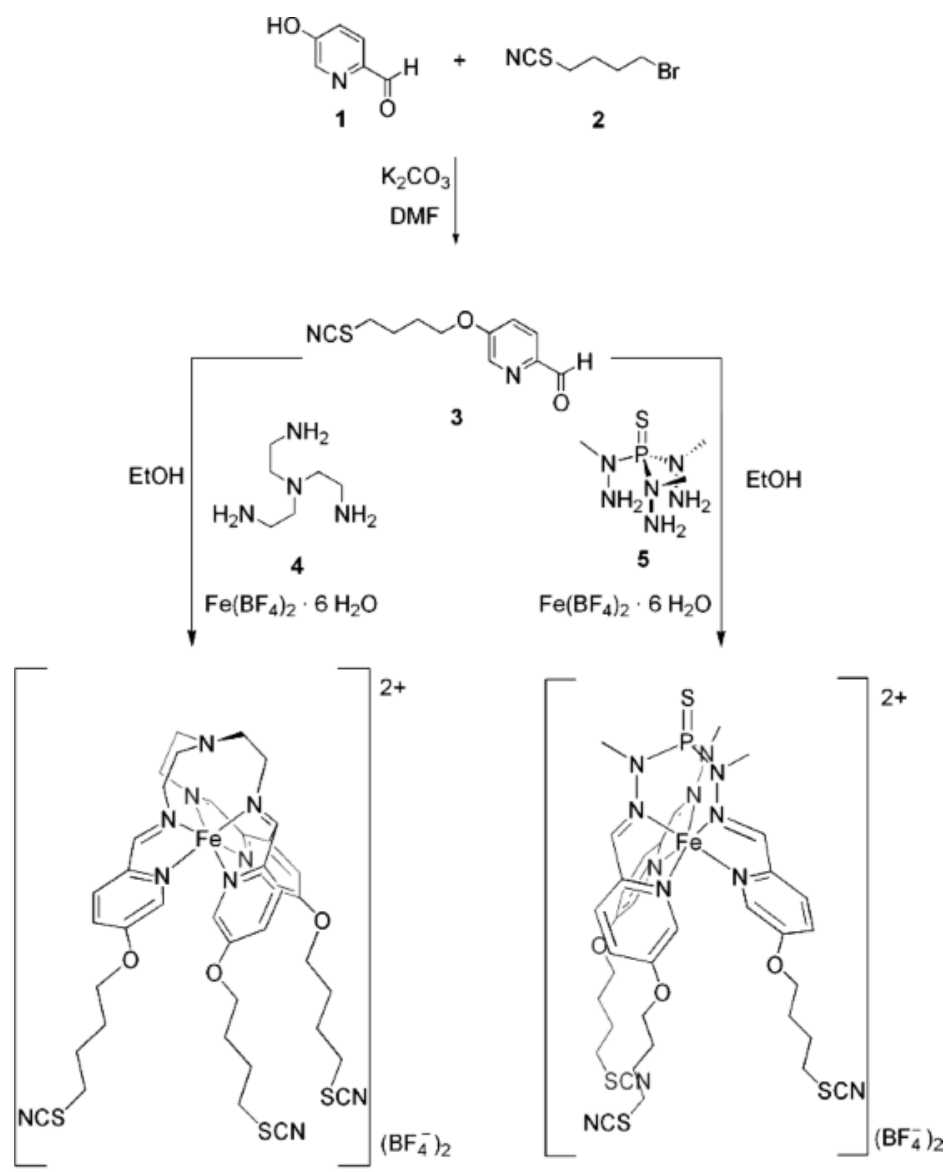

Scheme 2. Synthesis of the iron(II) complexes $6^{\mathrm{Fe}}$ and 7 ; reference compound $6^{\mathrm{Zn}}$ was obtained in an analogous fashion from reaction of $\mathrm{Zn}\left(\mathrm{ClO}_{4}\right)_{2} \cdot 6 \mathrm{H}_{2} \mathrm{O}$ with 3 and 4 . 
ogous zinc(II) complex, $\mathbf{6}^{\mathbf{Z n}}$ ). The aldehyde component 3, which carries the thiocyanate anchor, is obtained in tolerable yield by a Williamson ether synthesis, coupling the hydroxy-substituted pyridine carbaldehyde 1 and the bromobutane derivative 2 at $100^{\circ} \mathrm{C}$ in DMF (29\% yield). The $\left\{{ }^{1} \mathrm{H}\right\}{ }^{13} \mathrm{C}$ NMR spectrum of the product, 5-(4-thiocyanatobutoxy)pyridine2-carbaldehyde 3 (in $\mathrm{CDCl}_{3}$, r. t.; see Supporting Information, available online, for NMR spectra; see note at the end of the paper for availability), shows a characteristic resonance at $111.8 \mathrm{ppm}$, indicative of the $\mathrm{SCN}$ group (the ${ }^{13} \mathrm{C}$ resonance for the thiocyanate substituent in $\mathbf{2}$ is at $111.6 \mathrm{ppm})$. The presence of the SCN group in $\mathbf{3}$ was also confirmed by IR spectroscopy, where it gives rise to a strong absorption at $2154 \mathrm{~cm}^{-1}$. Resonances at $191.9 \mathrm{ppm}\left(\left\{{ }^{1} \mathrm{H}\right\}{ }^{13} \mathrm{C}\right.$ $\mathrm{NMR})$ and $9.97 \mathrm{ppm}\left({ }^{1} \mathrm{H} \mathrm{NMR}\right)$ are assigned to the aldehyde function.

The condensation of carbaldehyde 3 with the capping groups 4 or 5 was followed by ${ }^{1} \mathrm{H}$ NMR spectroscopy, tracking the disappearance of the aldehyde and primary amine proton resonances. Both condensation reactions were found to be complete within $60 \mathrm{~min}$. The subsequent complexation reactions of the tris-aldimines with $\mathrm{Fe}\left(\mathrm{BF}_{4}\right)_{2} \cdot 6 \mathrm{H}_{2} \mathrm{O}$ were performed at room temperature. Diagnostic resonances in the IR $\left(6^{\mathrm{Fe}}: 2152 \mathrm{~cm}^{-1} ; 7: 2150 \mathrm{~cm}^{-1}\right)$ and $\left\{{ }^{1} \mathrm{H}\right\}{ }^{13} \mathrm{C} \mathrm{NMR}$ spectra $\left(\mathbf{6}^{\mathbf{F e}}\right.$ : 112.0 ppm; 7: $\left.113.5 \mathrm{ppm}\right)$ of the resulting complexes show that the surface-active thiocyanate groups of the ligands are conserved in the complex (a)

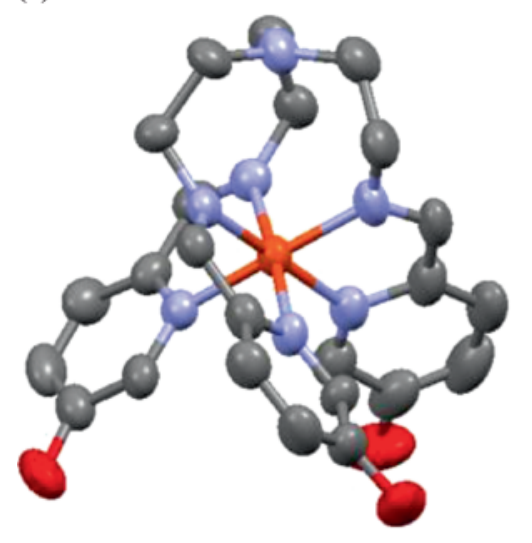

(c)

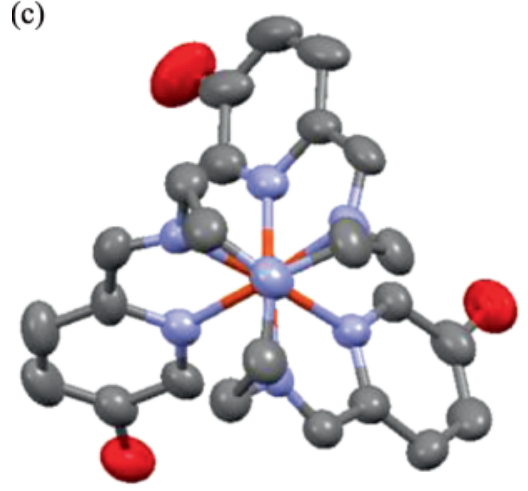

(b)

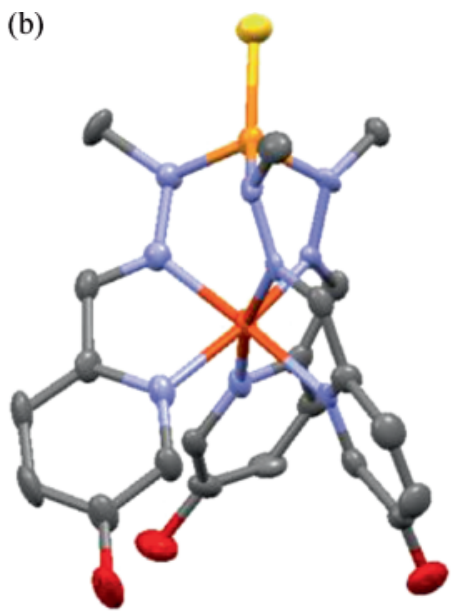

(d)

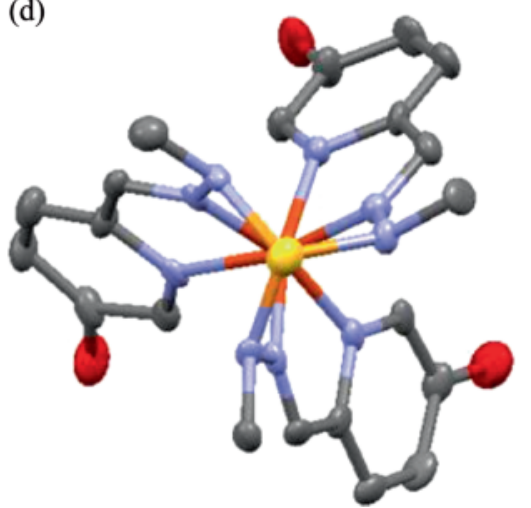

Fig. 1 (colour online). Ellipsoid models of the complex cation "head groups" in $\mathbf{6}^{\mathrm{Fe}}$ (left) and 7 (right) as side views (a and b) and projections along the pseudo-threefold axes (c and d); ellipsoids for 50\% probability, hydrogen atoms and 4-thiocyanatobutyl residues (some of which are severely disordered) omitted for clarity (colour code: brick red: Fe; blue: N; red: O; grey: C; yellow: S; orange: P). 
products. NMR shifts differ slightly because different solvents were used (see Supporting Information). In the $\left\{{ }^{1} \mathrm{H}\right\}{ }^{13} \mathrm{C}$ NMR spectrum of 7 , coupling of the $\mathrm{C}=\mathrm{N}$ and $N$-methyl carbon atoms with the phosphorus atom gives rise to doublets at $151.0 \mathrm{ppm}$ and $38.0 \mathrm{ppm}$, respectively. Coupling constants in both cases are very similar to those reported recently for the parent compound $\left[\mathrm{Fe}\left\{\right.\right.$ 'phos $(\mathrm{py})_{3}$ ' $\left.\}\right]\left(\mathrm{BF}_{4}\right)_{2}[41]$.

Single crystals of $\mathbf{6}^{\mathrm{Fe}} \cdot 1 / 4 \mathrm{Et}_{2} \mathrm{O}$ and $7 \cdot \mathrm{CH}_{3} \mathrm{CN}$ suitable for X-ray diffraction experiments were grown by precipitation of the salts from acetonitrile via diethyl ether vapour diffusion. In the refrigerator at $4{ }^{\circ} \mathrm{C}$, the process took ten months for $\mathbf{6}^{\mathrm{Fe}} \cdot 1 / 4 \mathrm{Et}_{2} \mathrm{O}$ and four days for $7 \cdot \mathrm{CH}_{3} \mathrm{CN}$. Compounds containing long alkyl chains with weakly interacting terminal groups may crystallise poorly. In our case, this caused two problems: Firstly, the crystal quality itself was low. This led to poor signal-to-noise ratios and, subsequently, to high $R_{\sigma}$ values (especially in the case of $7 \cdot \mathrm{CH}_{3} \mathrm{CN}$ ) and low numbers of observed reflections. Secondly, most of the 4-thiocyanatobutyl residues were severely disordered. In $6^{\mathbf{F e}} \cdot 1 / 4 \mathrm{Et}_{2} \mathrm{O}$, one of these residues could in fact not be handled with a discrete model at all; it had to be treated as a diffuse contribution to the overall scattering. Inspection of the electron count ( $\mathrm{ca}$. 66 excess electrons per unit cell) and the topology of the voids suggest the presence of an additional solvent molecule. As acetonitrile molecules usually are at least partially ordered, we propose the solvent is diethyl ether - being notorious for strong (correlated) disorder. In spite of these severe shortcomings, the coordination entities of $6^{\mathbf{F e}} \cdot 1 / 4 \mathrm{Et}_{2} \mathrm{O}$ and $7 \cdot \mathrm{CH}_{3} \mathrm{CN}$ are ordered and well-defined. MERCURY plots of the coordination entities of $6^{\mathbf{F e}} \cdot 1 / 4 \mathrm{Et}_{2} \mathrm{O}$ and $7 \cdot \mathrm{CH}_{3} \mathrm{CN}$ are shown in Fig. 1. Their structural parameters are summarised in Table 1.

Table 1. Selected average bond or interatomic lengths $(\AA)$, angles (deg), and dihedral angles (deg) for $\mathbf{6}^{\mathrm{Fe}}$ and 7 with standard deviations in parentheses.

\begin{tabular}{lll}
\hline & $\mathbf{6}^{\mathrm{Fe}}$ & $\mathbf{7}$ \\
\hline Distances & & \\
$d\left(\mathrm{Fe}-\mathrm{N}_{\text {imin }}\right)$ & $1.950(18)$ & $1.915(2)$ \\
$d\left(\mathrm{Fe}-\mathrm{N}_{\text {pyr }}\right)$ & $1.969(3)$ & $1.974(3)$ \\
$d(\mathrm{O} \cdots \mathrm{O})$ & $6.62(5)$ & $5.8(1)$ \\
Angles & & \\
$(\mathrm{N}-\mathrm{Fe}-\mathrm{N})_{\text {trans }}$ & $175.7(8)$ & $167.2(1)$ \\
$\Sigma_{c i s}{ }^{\mathrm{a}}$ & 61.6 & 60.7 \\
\hline
\end{tabular}

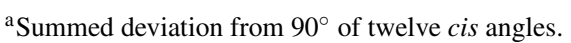

In both complex ions, average $\mathrm{Fe}-\mathrm{N}$ bond lengths around $1.95 \AA$ are indicative of a diamagnetic low-spin electron configuration for the iron(II) centre at $150 \mathrm{~K}$. The iron(II) centres are coordinated by six nitrogen donors in an octahedral fashion, with a slight distortion towards a trigonal prism in the case of 7 (see Fig. 1D). The trigonal distortion observed in $\mathbf{7}$ affects the directionality of the alkoxy spacers to some extent, as can be read from the non-bonded distances between the ether oxygen atoms of these spacers. These distances are significantly smaller for the trigonally distorted complex 7, and it is fair to assume that the same holds true for the non-bonded distances between the three -SCN anchors. Owing to severe disorder in the alkyl chains, however, a detailed discussion of geometric parameters in the ligand periphery of the solid-state structures is not warranted.

The magnetic behaviour of the complexes was studied as a function of temperature in the solid state and in solution. In the solid state (powdered samples, SQUID [superconducting quantum-interference device] magnetometer), complexes $\mathbf{6}^{\mathbf{F e}}$ and 7 were found to be diamagnetic across the whole temperature range $\left(6^{\mathrm{Fe}}\right.$ : 5-320 K; 7: 5-400 K; see Supporting Information, Figs. S8 and S9). The magnetic susceptibilities $\chi_{\mathrm{M}} T$ are in good agreement with the behaviour of the unsubstituted compounds $\left[\mathrm{Fe}\left\{\right.\right.$ 'tren $(\mathrm{py})_{3}$ ' $\left.\}\right]\left(\mathrm{BF}_{4}\right)_{2}$ [42] and $\left[\mathrm{Fe}\right.$ 'phos $(\mathrm{py})_{3}$ ' $\left.\}\right]\left(\mathrm{BF}_{4}\right)_{2}$ [44]. It cannot, however, be taken for granted that the bulk magnetic properties of the complexes will be conserved under conditions of reduced dimensionality, that is, when attached to a surface [45]. As was recently shown for an iron(II) SCO complex containing a related polypodal ligand, the thermodynamic SCO parameters undergo a marked change from the bulk values once the complex is adsorbed on pyrolytic carbon [18]. For complete characterisation, the complexes were also studied in free solution, and the results underscore the notion of largely diamagnetic behaviour.

The UV/Vis spectra of compounds $\mathbf{6}^{\mathrm{Fe}}$ and 7 at room temperature in methanol are typical of low-spin iron(II) complexes. Intense absorption bands with $\varepsilon_{\max }$ around $10^{4} \mathrm{M}^{-1} \cdot \mathrm{cm}^{-1}$ in the range $400-600 \mathrm{~nm}$ are observed (see below). This is the typical range for ${ }^{1} \mathrm{~A}_{1} \rightarrow{ }^{1}$ MLCT transitions in low-spin iron(II) complexes. The corresponding ${ }^{1} \mathrm{H}$ NMR spectra of $\mathbf{6}^{\mathbf{F e}}$ and 7 at room temperature exhibit well-resolved resonances, with chemical shifts $\delta<10 \mathrm{ppm}$ which, likewise, is the typical signature of diamagnetic com- 
pounds. Finally, diamagnetism of $\mathbf{6}^{\mathrm{Fe}}$ at room temperature is corroborated by comparison of its NMR spectra with the spectra of its intrinsically diamagnetic $\mathrm{Zn}^{\mathrm{II}}$ analogue, $\mathbf{6}^{\mathrm{Zn}}$. However, divergent NMRspectral properties are recorded for $6^{\mathrm{Fe}}$ and $6^{\mathbf{Z n}}$ at elevated temperatures (see Supporting Information, Figs. S10 and S11). Resonances of $\mathbf{6}^{\mathbf{F e}}$ experience low-field shifts with increasing temperature in $\left[\mathrm{D}_{7}\right]$ dimethyl formamide, pointing to the presence of paramagnetic components. No such shifts are observed for $6^{\mathbf{Z n}}$ under the same conditions. This divergence may indicate a beginning thermal spin crossover for $6^{\mathbf{F e}}$ at elevated temperatures.

Molecules of the type RSCN have previously been shown to produce well-ordered self-assembled thiolate monolayers on gold under suitable conditions, with a focus on simple alkyl chain or $\pi$ ring systems [36]. Adsorption of organic thiocyanates to gold has been proposed to proceed according to Eq. 1, which involves cleavage of the RSCN unit, with concomitant thiolate formation and partial dissolution of the substrate, ow-

\section{(a)}

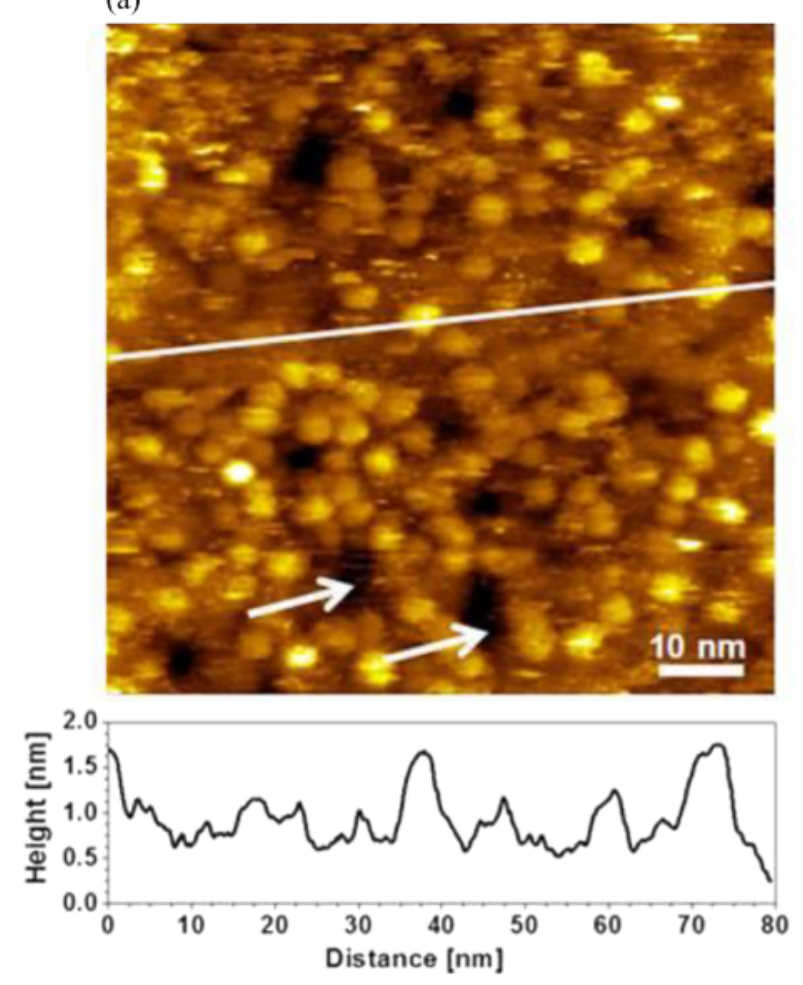

ing to the generation of dicyanoaurate [37].

$2 \mathrm{R}-\mathrm{SCN}+3 \mathrm{Au} \rightarrow\left[\mathrm{Au}(\mathrm{CN})_{2}\right]^{-}+2 \mathrm{R}-\mathrm{S}-\mathrm{Au}$

As is shown in the following, complexes $\mathbf{6}^{\mathbf{F e}}$ and 7 both adsorb to gold surfaces, but with greatly different results. The nature of the films has been analysed with respect to topology (using ellipsometry and STM), stoichiometry (XPS), and differential spectroscopic response (IRRAS and UV/Vis reflectance).

\section{Ellipsometry}

When analysing ellipsometric data for SAMs on gold, the question of the refractive index of the layer needs to be considered [46]. While a method exists to determine the thickness $d$ of a layer on a metallic substrate [47], light absorption from the substances under investigation here (see Fig. 2a) renders this method ambiguous. If any contribution from light absorption is neglected and a refractive index $n_{\mathrm{S}}$ of 1.5 is assumed

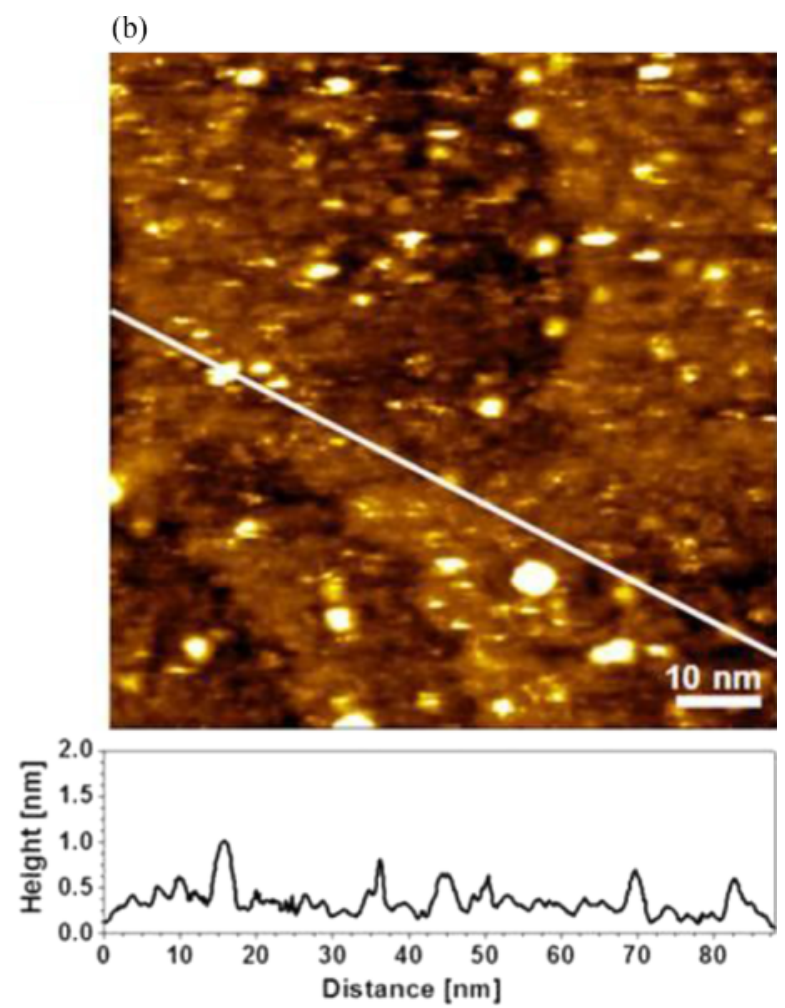

Fig. 2 (colour online). Scanning tunnelling microscopy images of $6^{\mathrm{Fe}}$ (a) and 7 (b) on $\mathrm{Au}(111) /$ mica, with corresponding height profiles indicated by lines. The samples were prepared at $338 \mathrm{~K}$ (immersion time: $1 \mathrm{~h}$; see text). 
(which is a typical value for organic compounds and metal-organic complexes), the values obtained for $d$ are 2.3 and $2.4 \mathrm{~nm}$, respectively, for $\mathbf{6}^{\mathbf{F e}}$ and 7 on gold. The longest dimensions of the molecules, however, are ca. $1.2 \mathrm{~nm}$ for $6^{\mathrm{Fe}}$ and $1.6 \mathrm{~nm}$ for 7 . Evidently, the layer thickness is larger than this longest dimension. Even when assuming a layer refractive index of 2.0, which should significantly overestimate the actual refractive index, a layer thickness of $1.4 \mathrm{~nm}$ is found for both $\mathbf{6}^{\mathrm{Fe}}$ and 7, which for $\mathbf{6}^{\mathbf{F e}}$ is still larger than the longest dimension of the molecule. Therefore, the layer adsorbed on gold cannot be a simple monolayer.

\section{Adsorbate characterisation by STM}

The STM image of $\mathbf{6}^{\mathbf{F e}}$ (Fig. 2a) is characterised by depressions (marked by arrows), with steps around $0.25 \mathrm{~nm}$ in height, and by protrusions of rather uniform diameter. The diameters of the protrusions $(>5 \mathrm{~nm})$ are significantly larger than the diameter of the cylinder to which the molecule may be approximated, which is $c a$. $0.7 \mathrm{~nm}$ (assuming the molecular $C_{3}$ axis to coincide with the $C_{\infty}$ axis of the cylinder). These results correlate with the results obtained by ellipsometry. Apparently, an interfacial transition layer with voids is present, which leads to a layer thickness greater than that expected for a monolayer containing the complexes with their $C_{3}$ axes vertical to the surface.

In principle, there may be several reasons for this behaviour. One is that several molecules are grouped together, thus forming small islands [17, 48]. However, if this were the case, one would not expect such a relatively narrow size distribution, unless specific geometries are preferred due to intermolecular interactions (for which we have no evidence). Another possible explanation is an imaging artefact. If the molecules are not rigidly anchored to the surface using all of their three 'legs', their radius of gyration would make the molecules appear bigger. This is consistent with our observation that the molecules are quite difficult to image, as the currents have to be close to the detection limit of the instrument. An anchoring through only one or two sulphur functions per molecule would be consistent with the substantial height variations. Since the height measured in STM results from a superposition of geometrical height and tunnelling probability, a variation in the number of anchors used per molecule would not only affect the geometrical arrangement but also the tunnelling channels. As the binding mecha- nism for thiocyanate-terminated compounds to gold involves partial dissolution of the substrate, the resulting complex interfacial morphology can be understood as a product of dissolution and adsorption. Metal dissolution, on the other hand, does not occur statistically over the full surface. Rather, dissolution starts at energetically favoured sites on the surface, $e . g$. at kinks or adatoms [49]. Therefore, the adsorbing species (undergoing thiocyanate-to-thiolate transformation, Eq. 1) preferentially forms in the vicinity of defects in the surface, which also explains the presence of residual -SCN observed in the IR spectra: not all ligands may be in the vicinity of a site suitable for $\left[\mathrm{Au}(\mathrm{CN})_{2}\right]^{-}$formation.

In contrast to compound $\mathbf{6}^{\mathrm{Fe}}$, we found no suitable set of conditions to prepare monolayers of compound 7 which would yield images comparable to Fig. $2 \mathrm{a}$. The imaging conditions were even more critical and the protrusions observed (Fig. 2b) were significantly lower in density and of lower height. These results are consistent with ellipsometry results, XPS and IRRAS (see below). These surface characterisation results suggest that compound 7 does not adsorb intact, a suggestion that is strongly corroborated by the $\mathrm{UV} / \mathrm{Vis}$ reflectance spectra to be discussed in the following.

\section{$U V /$ Vis reflectance spectroscopy}

The UV/Vis spectra of $\mathbf{6}^{\mathbf{F e}}$ in methanol solution and on a gold surface are displayed in Fig. 3 (for 7, see Supporting Information, Fig. S12). The spectrum of the solution of $6^{\mathbf{F e}}$ shows absorptions with maxima at 265, 300,370 and $540 \mathrm{~nm}$, the latter with a shoulder around $500 \mathrm{~nm}$. The peaks at 540, 500 and $370 \mathrm{~nm}$ are typical of $\left[\mathrm{Fe}\left\{\text { ' } \operatorname{tren}(\mathrm{py})_{3} \text { ' }\right\}\right]^{2+}\left(\mathrm{X}^{-}\right)_{2}$ complexes and are associated with the ${ }^{1} \mathrm{~A}_{1} \rightarrow{ }^{1}$ MLCT transition [50]. The peaks at 300 and $265 \mathrm{~nm}$ are assigned to $\pi \rightarrow \pi^{*}$ transitions of the aromatic moieties in the ligand. In the solution spectrum of 7 , these $\pi \rightarrow \pi^{*}$ transitions are present as well. The ${ }^{1} \mathrm{~A}_{1} \rightarrow{ }^{1}$ MLCT bands of 7 appear at higher energy. The lowest wavelength peak is visible as a shoulder centred at $370 \mathrm{~nm}$ in the ligand bands, while further peaks are present at 450 (shoulder) and $490 \mathrm{~nm}$. The UV/Vis spectrum of 7 is also in good agreement with the unsubstituted complex $\left[\mathrm{Fe}^{\prime} \operatorname{phos}(\mathrm{py})_{3}\right.$ ' $\left.\}\right]\left(\mathrm{BF}_{4}\right)_{2}$.

The reflectance spectra of $\mathbf{6}^{\mathbf{F e}}$ (Fig. 3b) and 7 (Fig. S12, see Supporting Information) on $\mathrm{Au}(111)$ are dominated by a rising baseline from 300 to $500 \mathrm{~nm}$. 


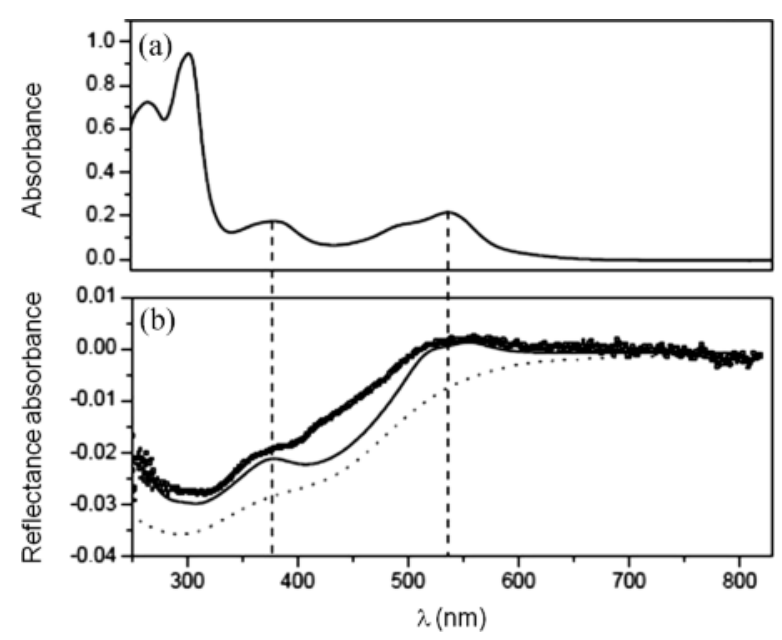

Fig. 3. UV/Vis spectra of $6^{\mathbf{F e}}$; (a) measured in transmission in methanol solution; (b) measured in reflection on $\mathrm{Au}(111)$; dotted line: simulation of a non-absorbing layer $(2.4 \mathrm{~nm}$ thick; refractive index 1.5) on $\mathrm{Au}$; solid line: simulation of a spectrum with five harmonic oscillators having resonance frequencies as obtained from (a).

This change in baseline is due to the spectral characteristics of the gold substrate, and can be reproduced in simulations of the reflectance absorbance. These simulations employ a transfer matrix method to compute the reflectivities of modified and unmodified gold surface, and compute the expected reflectance absorbance as in the measurement process $[51,52]$. Bulk optical constants of gold are used in the simulations [53]. For the surface modification, an isotropic layer of thickness $2.4 \mathrm{~nm}$ and a wavelength-independent refractive index of 1.5 were assumed to be adsorbed to gold. These parameters described the obtained ellipsometric data quite well. For such a system, the dotted line in Fig. 3b shows the same slope in the baseline as present in the experimental data, indicating that this feature is not related to absorptions from a layer adsorbed to the surface. In order to understand the effects that a surface layer of finite absorbance has on the shape of the spectra, simulations were carried out in which the dielectric function of the layer was represented by a sum of five harmonic oscillators. Input parameters for oscillator frequency and width were obtained by fitting the UV/Vis spectrum in solution (Fig. 3a and Supporting Information, Fig. S13a) with a sum of Lorentzian peaks. Absorption features from the molecules deposited on the surface show as additional peaks on top of the baseline.
For $\mathbf{6}^{\mathrm{Fe}}$ on $\mathrm{Au}(111)$, the spectral simulations (solid line in Fig. 3b) show that features present in the visible region of the solution spectra can also be found after adsorption. The oscillator strength of the five peaks was adjusted to reproduce the observed features semi-quantitatively. The UV/Vis reflectance spectra for $6^{\mathrm{Fe}}$ show the presence of all three ${ }^{1} \mathrm{~A}_{1} \rightarrow{ }^{1} \mathrm{MLCT}$ absorptions at 370,500 and $540 \mathrm{~nm}$, which are typical of $\left[\left\{\mathrm{Fe}^{\prime} \operatorname{tren}(\mathrm{py})_{3}{ }^{\prime}\right\}\right](\mathrm{X})_{2}$ complexes [50]. When comparing the simulations and the reflection spectra, the peaks with maxima in solution at 500 and $540 \mathrm{~nm}$ experience a slight red shift on $\mathrm{Au}(111)$, by $\sim 15 \mathrm{~nm}$. Whereas the solution spectra are dominated by the strong intraligand modes at 265 and $300 \mathrm{~nm}$, the ${ }^{1} \mathrm{~A}_{1} \rightarrow{ }^{1} \mathrm{MLCT}$ transitions at 500 and $540 \mathrm{~nm}$ dominate the reflection spectra. The intensity ratio $\left({ }^{1} \mathrm{~A}_{1} \rightarrow{ }^{1} \mathrm{MLCT} /\right.$ intraligand $)$ is $\sim 50$ times higher on the surface than in solution. This strong change in relative intensities may be caused by one or several of the following factors; (a) stronger intermolecular interactions on $\mathrm{Au}(111)$ as compared to dilute solution; (b) coupling of states in the adsorbates to states in the metallic solid ("Fano resonance") [54]; or (c) the orientation of the molecules on the metal surface is such that it does not enable an excitation of the respective transition. The latter is a direct consequence of the surface selection rule, which states that, on a metallic surface, only transition dipole moment components perpendicular to the surface can be excited, and these can only be excited using $p$-polarisation at high incidence angles [55]. A comparison of the simulated and the measured spectra in Fig. $3 \mathrm{~b}$ shows that there is considerable disagreement in the region around $450 \mathrm{~nm}$. This may originate from an interface state that is present only after adsorption of the complexes to $\mathrm{Au}(111)$, but not in the dissolved molecules. Nevertheless, the clear observation of the ${ }^{1} \mathrm{~A}_{1} \rightarrow{ }^{1} \mathrm{MLCT}$ absorptions indicates that the units $\left[\mathrm{Fe}\left\{\right.\right.$ 'tren $\left(\mathrm{pyOC}_{4} \mathrm{~S}\right)_{3}$ ' $\left.\}\right]\left(\mathrm{BF}_{4}\right)_{2}$ are intact and in the low-spin state after adsorption on gold.

For 7 on $\mathrm{Au}(111)$ (see Supporting Information, Fig. S12b) only one transition at $370 \mathrm{~nm}$, reminiscent of the ${ }^{1} \mathrm{~A}_{1} \rightarrow{ }^{1}$ MLCT mode, can be detected on gold. A comparison with simulation on the basis of solution spectra shows qualitative differences, and no peak observed in solution is found after adsorption to $\mathrm{Au}(111)$. This is a clear indication of complex degradation upon contact with the gold surface. Further support for the diverging behaviour of $6^{\mathrm{Fe}}$ and 7 stems from the IR response of the thin surface films (Fig. 4). In summary, 


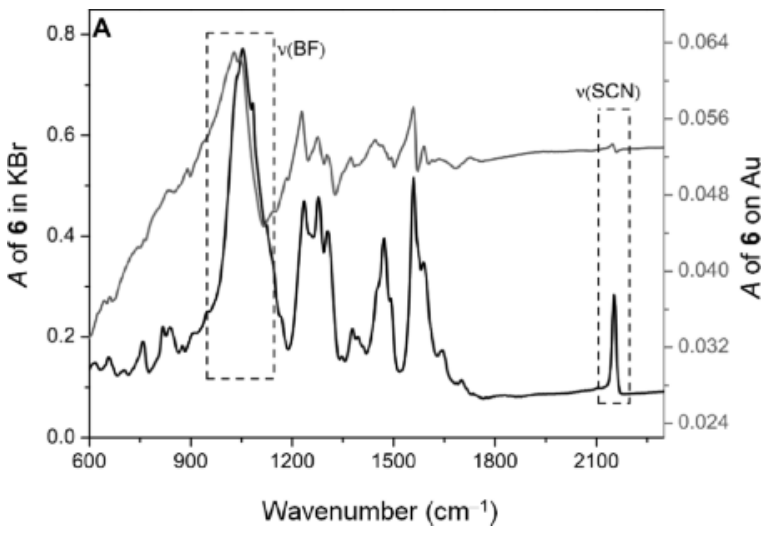

Fig. 4. IR spectra of compound $\mathbf{6}^{\mathbf{F e}}$. Characteristic absorptions are highlighted by dashed boxes. Grey: sample layer on gold. Black: sample measured as $\mathrm{KBr}$ disc.

only for complex $\mathbf{6}^{\mathrm{Fe}}$ is the spectral response of the $\left[\mathrm{MN}_{6}\right]$ chromophore conserved after immobilisation.

Infrared reflectance absorbance spectroscopy (IRRAS)

IRRAS was employed in order to probe the binding of compounds $\mathbf{6}^{\mathbf{F e}}$ and $\mathbf{7}$ to gold. As implied by Eq. 1, exhaustive surface binding of the complexes via all three arms would not give rise to any residual resonances due to RSCN. The IR spectrum of a sample of $6^{\mathrm{Fe}}$ on gold shows a small dispersive peak at $2152 \mathrm{~cm}^{-1}$ (Fig. 4). Weak signals in this range (i.e., at $2160 \mathrm{~cm}^{-1}$ ) have been commonly observed upon surface grafting of thiocyanates on gold [56]. They have been assigned to surface-bound cyanoaurate. A complementary interpretation of the resonance in terms of the $\mathrm{CN}$ stretching vibration of residual thiocyanate appears equally reasonable. The latter assignment implies that thiolate formation on gold, with concomitant evolution of dicyanoaurate $\left(\left[\mathrm{Au}(\mathrm{CN})_{2}\right]^{-}\right.$, see Eq. 1), may not be quantitative. However, the appearance of the characteristic $\mathrm{B}-\mathrm{F}^{-}$absorption at $1054 \mathrm{~cm}^{-1}$ (due to the $\mathrm{BF}_{4}^{-}$counterion), as well as the good agreement of the finger print areas between the spectra measured on gold and as a $\mathrm{KBr}$ disc, show the surface-deposited complex to be intact. XPS measurements were carried out on samples of $\mathbf{6}^{\mathbf{F e}}$ deposited on gold, in order to confirm this result and elucidate the binding tendency of the SCN groups.

In contrast, the IR spectra of $\mathbf{7}$ as deposited on gold and as measured in a $\mathrm{KBr}$ disc are incommensurate with a maintained chemical identity (Fig. S13, see Supporting Information). This result again suggests that compound 7 decomposes upon contact with the gold surface, either because of an undesirable reaction with the solvent DMF (ethanol was impractical, owing to poor solubility of 7), or a reaction of the thiophosphoryl moiety with the Au substrate. To check for decomposition of the capping unit of $\mathbf{7}$ in contact with $\mathrm{Au}$, the complex $\left.\left[\mathrm{Fe}\{\text { 'phos(py) })_{3}\right\}\right]\left(\mathrm{BF}_{4}\right)_{2}$ has been used. It is structurally similar to 7 but has no thiocyanate groups and no alkyl spacers [41]. Layered gold surfaces prepared under the same conditions show strong IR absorptions at 1310 and $1265 \mathrm{~cm}^{-1}$ and spectra substantially different from the base compound (for the molecular structure and IRRAS spectra, Figs. S14 and S15, see Supporting Information). In particular, the strong B-F stretching mode at $1054 \mathrm{~cm}^{-1}$ is absent. XPS of these surfaces is also quite different from the expected spectra (see Fig. S16, in the Supporting Information, for a survey scan). Hence, upon exposure of ligands containing $\mathrm{P}=\mathrm{S}$ groups to gold surfaces, an unknown reaction leads to decomposition of the complex and adsorption of a decomposition product. Accordingly, the response of compound 7 adsorbed to gold towards Xray impact was below the detection level.

\section{$X$-Ray photoelectron spectroscopy (XPS)}

The chemical composition of the thin films of $\mathbf{6}^{\mathrm{Fe}}$ on $\mathrm{Au}(111)$ has been studied by X-ray photoelectron spectroscopy, and a satisfactory agreement obtained between the surface stoichiometry of the complex unit of $6^{\mathbf{F e}}$ and its chemical composition in the bulk (see Table 2).

Sulphur speciation: The complexity of the S $2 p$ spectrum of $6^{\mathbf{F e}}$ adsorbed to gold clearly indicates that more than one sulphur species is present in this system. A quantitative description of the spectrum requires a set of four sulphur doublets which is shown in Fig. 5A. Beside thiolate represented by the doublet at $161.8 \mathrm{eV}$ and $163 \mathrm{eV}$ (component 1 in Fig. 5A) [38, 57-59], additional species reflected by the $\mathrm{S} 2 p_{3 / 2}$ signals located at $161,163.4$ and $164.8 \mathrm{eV}$ are present. The peak at $161 \mathrm{eV}$ has been repeatedly observed in thiol SAMs to varying extents [57-61] and its detailed interpretation remains elusive [62]. While atomic sulphur has been suggested [63], this is rather unlikely under the preparation conditions used here, and the alter- 
Table 2. Assignment of features in the XPS spectra of compound $6^{\mathrm{Fe}}$ on gold (atomic ratios are given relative to iron).

\begin{tabular}{lll}
\hline Core level & $\begin{array}{l}\text { Binding energy (eV) } \\
\text { [contribution in \%] }\end{array}$ & $\begin{array}{l}\text { Atomic ratios: } \\
\text { Exp. (theory) }\end{array}$ \\
\hline Fe $2 p_{3 / 2}$ & 708.9 & $1.0(1.0)$ \\
$\mathrm{O} 1 s$ & $533.2[56.3]$ & $5.0(3.0)$ \\
& $531.7[43.7]$ & \\
$\mathrm{N} 1 s$ & 399.7 & $6.6(7.0)$ \\
$\mathrm{B} 1 s$ & 194.2 & $0.9(2.0)$ \\
$\mathrm{F} 1 s$ & 685.7 & $3.8(8.0)$ \\
$\mathrm{S} 2 p_{3 / 2}$ & $161.0[18.8]$ & $2.6(3.0)$ \\
& $161.8[45.4]$ & \\
& $163.4[17.8]$ & \\
$\mathrm{C} 1 s$ & $164.8[18.0]$ & $36.3(39.0)$ \\
& $284.7[33.3]$ & \\
& $285.7[50.0]$ & \\
\hline
\end{tabular}

native interpretation of a different bonding configuration of thiolate is favoured [57-60, 62]. Interestingly, in some studies this signal appears only in the initial stages of thiol adsorption $[58,60]$, when the monolayer is still incomplete. This is consistent with the STM observation that the films are rather disordered and not densely packed. In contrast to these thiolaterelated peaks whose positions are clearly defined in the spectrum, the positions of the other peaks at higher binding energies, which have also been observed for alkanethiocyanates $[37,38]$, are less precisely defined due to the width of the features. Therefore, a fit in this range is a phenomenological description rather than an accurate identification of species. Nevertheless these features, which fall in a range also observed for disulphides [57], reveal that not only thiolate species are present but also unbound sulphur groups. The exact origin is difficult to pin down as free thiols, thioethers and disulphides appear at rather similar energies. However, disulphides formed by intra- or intermolecular coupling of the functional groups are the most likely species. The occurrence of sulphur species not bound to the Au substrate is again in agreement with the literature, as molecules with three potential anchoring groups have previously been shown to bond to a gold surface in other than tripodal fashion $[23,61]$.

Boron and fluorine speciation: The $\mathrm{F} 1 s$ spectrum (Fig. S17A, see Supporting Information) shows only a single fluorine species at $685.7 \mathrm{eV}$. The same holds for the B $1 s$ spectrum with a peak at $194.2 \mathrm{eV}$ (Fig. S17B, see Supporting Information). The peak positions are consistent with the values reported in the lit- erature for $\mathrm{BF}_{4}^{-}$[64], and the measured $\mathrm{F}: \mathrm{B}$ atomic ratio close to the theoretical ratio of $4: 1$ further corroborates the co-adsorption of this anion with the iron complex. However, the measured amounts of both fluorine and boron are significantly smaller than expected and come to only about $50 \%$ of the stoichiometric value.

Iron and nitrogen speciation: The single narrow peak observed for the Fe $2 p_{3 / 2}$ signal (Fig. 5B) is indicative of a single species and suggests that the complex adsorbs intact. The binding energy indicates an iron(II) species [65], as inferred from comparison with other complexes where the iron(II) ion is coordinated
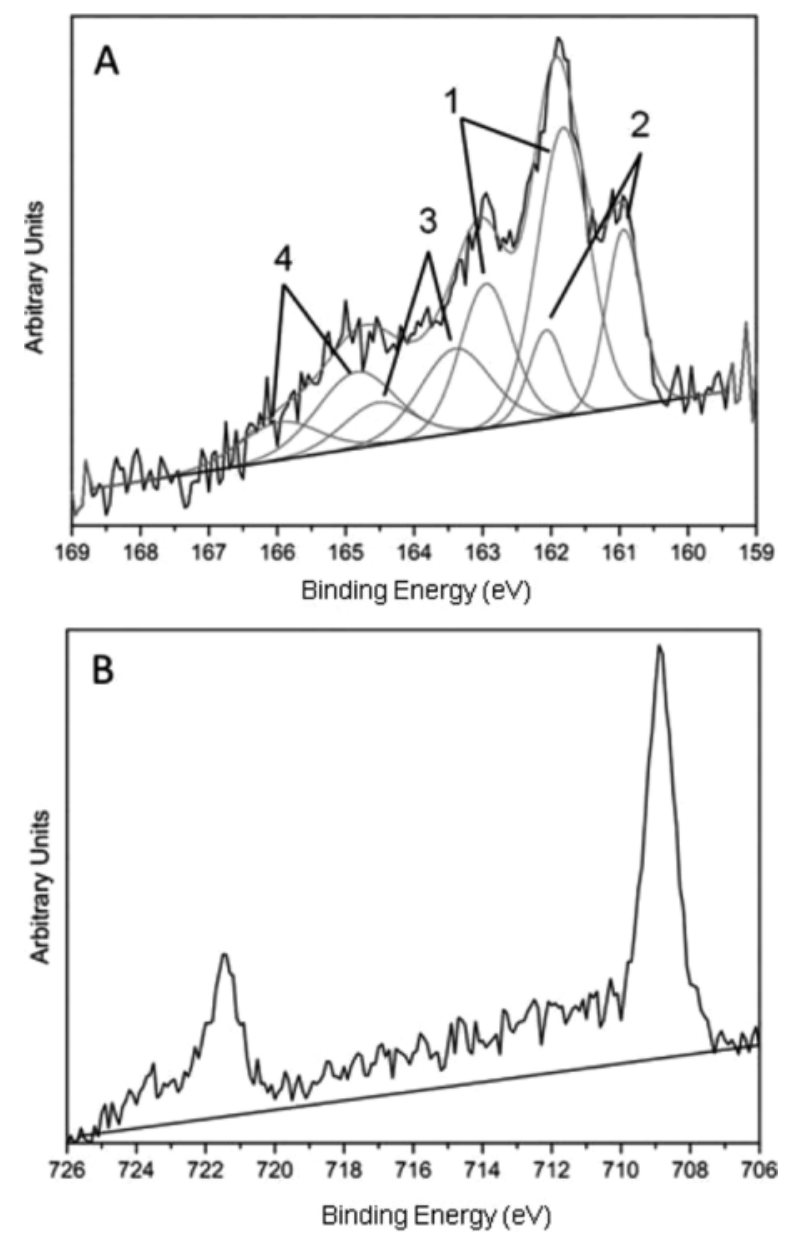

Fig. 5. XPS spectra of a layer of $\mathbf{6}^{\mathbf{F e}}$ adsorbed on $\mathrm{Au}(111)$ : (A) S $2 p$ with doublets of the components labelled, (B) Fe $2 p$ (all spectra show the baselines used to calculate the intensity of the signals; for b $1 s, \mathrm{C} 1 s, \mathrm{~F} 1 s, \mathrm{O} 1 s$ and $\mathrm{N} 1 s$, see Fig. S17 in the Supporting Information). 
to nitrogen ligands, such as phthalocyanines or porphyrins $[66,67]$. That the complex adsorbs intact may also be inferred from the nitrogen signal, whose intensity is close to the stoichiometric ratio. The signal can be described by a single peak centred at $399.7 \mathrm{eV}$ with a half width of $1.6 \mathrm{eV}$ (Fig. S17C, see Supporting Information).

Its position is higher in energy than the signal expected for pyridine nitrogen, but lower than for protonated nitrogen species $[68,69]$. The peak width is greater than for a single nitrogen species, as expected, considering that the molecule contains three different types of nitrogen atoms, $i$. e. imine, tertiary amine and aromatic N. While it poses no problem to fit the spectrum to three peaks instead of one when taking the proper stoichiometry into account, we have refrained from doing so; no additional information would be gained in view of the close proximity of the binding energies.

Oxygen speciation: The O $1 s$ signal (Fig. S17D, Supporting Information) clearly consists of more than one component and can be fitted to two peaks at 533.2 and $531.7 \mathrm{eV}$, respectively. The total amount of oxygen is well above what is expected from the stoichiometry. However, comparison of the intensity of the peak at $533.2 \mathrm{eV}$, which is assigned to the ether group in the molecule $[70,71]$, with the iron signal yields a ratio close to the expected value of $3: 1$. The energy of $531.7 \mathrm{eV}$ of the second peak is in the range for the $\mathrm{OH}^{-}$ species [64]. Since there is a deficiency in the amount of $\mathrm{BF}_{4}^{-}$, as mentioned above, our interpretation is that the tetrafluoroborate anion has been partially replaced by hydroxide ions. Formation of hydroxide ion during the adsorption of thiocyanate on gold in previous studies has been suggested to be due to the reduction of residual oxygen (Eqs. 2, 3) [56].

$$
\begin{aligned}
& 2 \mathrm{CN}^{-}+\mathrm{Au} \rightarrow\left[\mathrm{Au}(\mathrm{CN})_{2}\right]^{-}+\mathrm{e}^{-} \\
& \mathrm{O}_{2}+2 \mathrm{H}_{2} \mathrm{O}+4 \mathrm{e}^{-} \rightarrow 4 \mathrm{OH}^{-}
\end{aligned}
$$

Carbon speciation: The C $1 s$ spectrum (Fig. S17E, see Supporting Information) is characterised by a broad peak centred at $285.6 \mathrm{eV}$ which results from a superposition of at least three carbon signals. There is the contribution from aliphatic and aromatic carbon atoms with binding energies below $285 \mathrm{eV}$. Another signal between 285.5 and $286.0 \mathrm{eV}$ comes from the imine carbon and the carbon atoms in the ortho and para po- sitions of the pyridine ring [27, 68, 69]. A third component above $286 \mathrm{eV}$ originates from carbon atoms in the ether group [72]. Taking the stoichiometry into account, the carbon signal can be described by the components shown in Fig. S17E (see Supporting Information) and the peak positions given in Table 1 . We note that, due to the number of different carbon atoms, the components shown in Fig. S17E should not be taken as a rigorous analysis but rather an illustration of the different regions.

\section{Conclusion}

The main goal of this work has been the covalent deposition of salt-like iron(II) complexes on $\mathrm{Au}(111)$ surfaces. The approach has relied on tripodal complex topologies, which implies surface grafting via all three anchor groups. Thiocyanate anchors have been established as 'masked' thiol surrogates in order to prevent interference of the surface-adsorbing functional group with the central metal of the complex. To this end, two new iron(II) complexes ( $6^{\mathbf{F e}}$ and 7 ) have been synthesised and fully characterised. The modular synthetic approach chosen provides access to these complex topologies in reasonable time and high yields. The magnetic behaviour of the compounds has been investigated in the bulk and in dilute solution; in the latter, the complexes are present as isolated units. Both bulk compounds are diamagnetic in the temperature range from 5 to above $300 \mathrm{~K}$, whereas $\mathbf{6}^{\mathbf{F e}}$ shows signs of a beginning thermal spin crossover when studied in solution at elevated temperatures.

The STM images of thin films of the compounds deposited on $\mathrm{Au}(111)$ show little order but a complex surface morphology. This can be understood on the basis of metal dissolution followed by complex adsorption. Such a "dissolution-adsorption" mechanism is consistent with the observation of residual thiocyanate resonances in the IR spectra and the speciation in the sulphur XPS spectra and is a typical feature of thiocyanate/Au(111) conjugates. XPS and IR data reveal the presence of residual SCN groups in the layer, pointing to incomplete thiolate formation. Both techniques reveal the presence of $\mathrm{BF}_{4}^{-}$counterions. XPS detects all expected kinds of atoms of complex $\mathbf{6}^{\mathbf{F e}}$ on the surface and satisfyingly mimics the stoichiometry of the complex unit. While compound 7 decomposes upon exposure to gold in an as yet incompletely understood manner, compound $\mathbf{6}^{\mathbf{F e}}$ adsorbs 
intact. This conclusion integrates results from XPS, IR, and, in particular, from UV/Vis spectroscopic measurements.

The conservation of the intense metal-to-ligand charge-transfer bands in the surface-bound state is the single-most critical requirement for the utilisation of iron(II) complexes as functional units on metal surfaces. The reason for this is threefold: (i) 'Optical addressability' of a functional unit on a surface requires its chromophore(s) to be susceptible to light absorption by virtue of the surface-selection rules of optical dipolar transitions. While this is true for the ${ }^{1}$ MLCT transitions of $\mathbf{6}^{\mathrm{Fe}}$, the respective intra-ligand transitions are almost completely quenched. This finding is at odds with the anticipated 'lunar modules' surface geometry suggested by M. Mayor et al. [23]. Rather, it favours a severely tilted geometry; (ii) conservation of the complex chromophore indicates the coordination environment of iron in compound $\mathbf{6}^{\mathbf{F e}}$ to be intact after deposition on the surface; (iii) importantly, the conserved spectral features also indicate the surface-bound complexes to be in their low-spin configuration, in the same way as in the bulk. Strategies to anchor molecules to surfaces through "multipoint interactions" remain very attractive, as surface layers thus produced are expected to be robust, and allow a high degree of spatial control. Our present work illustrates a number of important problems that must be overcome if this approach is to come to fruition. Future work aims to identify design principles where the programmed multipoint adsorption of complexes on surfaces is integrated with non-covalent lateral, inter-complex interactions.

\section{Experimental Section}

Unless noted otherwise, all reactions were carried out in dried solvents under dry dinitrogen, using standard Schlenk techniques. Reagents were purchased from Aldrich or Acros and used without further purification. Spectroscopic data were obtained using the following instruments: IR ( $\mathrm{KBr}$ discs): Nicolet Magna System 750; surface measurements (reflection on gold): Bruker Vertex 70V, liquid nitrogencooled MCT detector; NMR: Bruker ARX 200, ARX 400; MS (ESI): Orbitrap LTQ XL, Thermo Scientific. Elemental analyses (C, H, N, S) were carried out by combustion analysis using a Thermo Finnigan EAGER 300 (Flash 1112) apparatus. UV/Vis spectra in solution were measured with a Varian Cary 50 spectrometer, equipped with a UV/Vis quartz immersion probe (light path $1 \mathrm{~mm}$, Hellma), in a home-built measuring cell.

Monolayer preparation: Ethanol (analytical reagent grade) was degassed with nitrogen prior to monolayer preparation. Au substrates: $300 \mathrm{~nm}$ - thick epitaxial gold layers were vapour-deposited onto mica and flame-annealed before immersion into solution. Resulting surfaces from this preparation procedure are known to be predominantly $\mathrm{Au}(111)$ [75]. Layers of the iron complexes were prepared by immersing substrates at $338 \mathrm{~K}$ for $1 \mathrm{~h}$, into a $0.4 \mathrm{mM}$ solution of $6^{\mathbf{F e}}$ in ethanol, or a $0.4 \mathrm{mM}$ solution of $\mathbf{7}$ in DMF. Substrates were then removed, rinsed with pure ethanol, and dried in a stream of dry dinitrogen.

STM: STM measurements were carried out in air using a PicoPlus Microscope (Molecular Imaging). Tips were prepared by mechanically cutting a $0.25 \mathrm{~mm} \mathrm{Pt} / \mathrm{Ir}$ wire. STM images were recorded in constant current mode using a bias voltage between 0.5 and $1.0 \mathrm{~V}$ and currents below $2 \mathrm{pA}$.

$X$-Ray photoelectron spectroscopy (XPS): All XPS measurements were performed on the Kratos Axis Ultra DLD spectrometer at Sasol Technology (UK) Ltd., St. Andrews. The instrument is equipped with a monochromated X-ray source $\left(\mathrm{AlK}_{\alpha}, h v=1486.6 \mathrm{eV}\right)$ operating at $30 \mathrm{~W}$. This low operating power was found necessary to minimise any potential $\mathrm{X}$-ray beam damage to the films. Au spectra were acquired in order to provide the $\mathrm{Au} 4 f_{7 / 2}$ peak energy at $83.9 \mathrm{eV}$ as a reference. All the quantifications were done taking the relative sensitivity factors into account. Peak fitting was performed with the CasaXPS software using a Lorentzian to Gaussian ratio of 0.30 . The energy separation $\mathrm{S} 2 p_{3 / 2}-\mathrm{S} 2 p_{1 / 2}$ was held constant at $1.13 \mathrm{eV}$, and the relative intensities of each doublet peak were taken to be equal to the ratio of their respective degeneracies $(2: 1)$.

UV/Vis reflectance spectroscopy and ellipsometry: Spectroscopic ellipsometry and UV/Vis reflectance spectra were measured using a Sentech SE-800 spectroscopic ellipsometer. UV/Vis reflectance spectra at an angle of incidence of $80^{\circ}$ in $p$-polarisation were obtained using the following procedure: The retarder was removed from the beam path of the spectroscopic ellipsometer, and both polariser and analyser were set to $p$-polarisation. The raw intensities $I_{\text {mod }}$ of the modified samples were recorded. Using the same setting for the integration time, the detector dark current $I_{\text {dark }}$ was measured. In a reference measurement, the reflected intensity $I_{\text {ref }}$ from an unmodified, freshly prepared gold surface was recorded. The reflectance absorbance was then computed as $-\log _{10}\left(\left(I_{\text {mod }}-I_{\text {dark }}\right) /\left(I_{\text {ref }}-I_{\text {dark }}\right)\right)$. $p$-Polarisation 
at high incidence angles was used in order to probe transition dipole moment components that are perpendicular to the surface. Only these can be excited on a metallic surface [55]. Spectroscopic ellipsometry at angles of incidence of $50^{\circ}$ and $70^{\circ}$ was used to determine the thickness $d$ of the adsorbed layers. Briefly, the experiment measures the ratio $r_{\mathrm{p}} / r_{\mathrm{s}}=\tan (\Psi) \mathrm{e}^{i \Delta}$ (with $i=(-1)^{0.5}$ ) between amplitude reflection coefficients $r_{\mathrm{p}}$ for $p$ - and $r_{\mathrm{s}}$ for $s$-polarised light. This ratio is expressed using the two ellipsometric angles $\Psi$ and $\Delta[76,77]$. The difference between treated samples and an unmodified gold surface was analysed. For a layer which is thin compared to the wavelength of light, with refractive index $n_{\mathrm{s}}$, the difference in $r_{\mathrm{p}} / r_{\mathrm{s}}$ between covered and uncovered surface is directly related to the first order perturbation parameter, $J_{1}=d\left(1-n_{s}^{2}\right)\left(n_{s}^{2}-n_{\mathrm{Au}}^{2}\right) / n_{s}^{2}$ [51]. The wavelength-dependent values of the refractive index $n_{\mathrm{Au}}$ of gold were taken from the literature [52].

5-(Hydroxy)picolinaldehyde (1), 1-bromo-4-thiocyanatobutane (2), and $1,1^{\prime}, 1^{\prime \prime}$-trimethyl(thiophosphoryl)trihydrazide (5) were prepared as described in the literature [43, 73, 74].

Synthesis of 5-(4-thiocyanatobutoxy)pyridine2-carbaldehyde (3)

A mixture of 5-(hydroxy)picolinaldehyde $(\mathbf{1} ; 51 \mathrm{mg}$, $0.4 \mathrm{mmol}), \quad 1$-bromo-4-thiocyanatobutane $\quad(2 ; 119 \mathrm{mg}$, $0.6 \mathrm{mmol})$ and anhydrous potassium carbonate $(72 \mathrm{mg}$, $0.5 \mathrm{mmol}$ ) was stirred vigorously in $N, N$-dimethyl formamide $(6 \mathrm{~mL})$ at $100^{\circ} \mathrm{C}$ for $4 \mathrm{~h}$. After the mixture had cooled to room temperature, water $(18 \mathrm{~mL})$ was added, the suspension extracted with diethyl ether $(3 \times 10 \mathrm{~mL})$, and the combined extracts dried over $\mathrm{Na}_{2} \mathrm{SO}_{4}$. The solvent was evaporated on a rotary evaporator and the residue purified by column chromatography on silica gel using hexane-ethyl acetate $(1: 1)$ as eluent $\left(R_{\mathrm{f}}=0.42\right)$ to give thiocyanate $\mathbf{3}$ as a yellow oil $(43 \mathrm{mg}, 29 \%) .-{ }^{1} \mathrm{H} \mathrm{NMR}(400 \mathrm{MHz}$, [D]chloroform, $25^{\circ} \mathrm{C}$ ): $\delta=9.97$ (s, $1 \mathrm{H} ; \mathrm{CHO}$ ), 8.41 (dd, $\left.J=2.4,0.5 \mathrm{~Hz}, 1 \mathrm{H} ; \mathrm{H}_{\text {Aryl }}\right), 7.95(\mathrm{dd}, J=8.2,0.6 \mathrm{~Hz}, 1$ $\mathrm{H} ; \mathrm{H}_{\text {Aryl }}$ ), 7.28 (ddd, $J=8.2,2.4,0.6 \mathrm{~Hz}, 1 \mathrm{H} ; \mathrm{H}_{\text {Aryl }}$ ), $4.15\left(\mathrm{t}, J=5.8 \mathrm{~Hz}, 2 \mathrm{H}\right.$; O- $\left.\mathrm{CH}_{2}-\right), 3.05(\mathrm{t}, J=6.8 \mathrm{~Hz}, 2$ $\mathrm{H}$; $\left.-\mathrm{CH}_{2}-\mathrm{SCN}\right), 2.08-2.01\left(\mathrm{~m}, 4 \mathrm{H}\right.$; $\left.-\mathrm{CH}_{2}-\mathrm{CH}_{2}-\right)$ ppm. ${ }^{13} \mathrm{C}$ NMR $\left(100.6 \mathrm{MHz},[\mathrm{D}]\right.$ chloroform, $\left.25^{\circ} \mathrm{C}\right): \delta=191.9$ (CHO), $158.0\left(\mathrm{C}_{\text {Aryl }}\right), 146.4\left(\mathrm{C}_{\text {Aryl }}\right), 138.6\left(\mathrm{C}_{\text {Aryl }}\right), 123.3$ $\left(\mathrm{C}_{\text {Aryl }}\right), 120.4\left(\mathrm{C}_{\text {Aryl }}\right), 111.9(\mathrm{SCN}), 67.7\left(\mathrm{O}-\mathrm{CH}_{2}-\right), 33.5$ $\left(-\mathrm{CH}_{2}-\mathrm{SCN}\right), 27.2\left(-\mathrm{CH}_{2}-\mathrm{CH}_{2}-\right), 26.6\left(-\mathrm{CH}_{2}-\mathrm{CH}_{2}-\right) \mathrm{ppm}$. - IR (MeOH): $v=2154(\mathrm{~s}), 1708(\mathrm{~s}), 1573(\mathrm{~s}) \mathrm{cm}^{-1}$.

Synthesis of tris[2-(\{[5-(4-thiocyanatobutoxy)pyridin-2-yl$\kappa N$ Jmethylene \}amino- $\kappa N)$-ethyl]amine \}iron(II) tetrafluoroborate $\left(6^{\mathrm{Fe}}\right)$

Tris-(2-aminoethyl)amine, 'tren', (4; $14 \mathrm{mg}, 0.1 \mathrm{mmol})$ was dissolved in methanol $(1 \mathrm{~mL})$ and the solution added to a solution of 5-(4-thiocyanatobutoxy)pyridine-2carbaldehyde $(3 ; 70 \mathrm{mg}, 0.3 \mathrm{mmol})$ in methanol $(2 \mathrm{~mL})$. The resulting solution was stirred at room temperature for $1 \mathrm{~h}$, before adding dropwise a solution of $\mathrm{Fe}\left(\mathrm{BF}_{4}\right)_{2} \cdot 6 \mathrm{H}_{2} \mathrm{O}$ $(33.7 \mathrm{mg}, 0.1 \mathrm{mmol})$ in methanol $(1.5 \mathrm{~mL})$. The resulting dark-red suspension was stirred at room temperature for $12 \mathrm{~h}$ and filtered, the remaining red solid washed with dry diethyl ether $(5 \mathrm{~mL})$ and dried in vacuo $(58 \mathrm{mg}, 58 \%)$. ${ }^{1} \mathrm{H}$ NMR $\left(400 \mathrm{MHz},\left[\mathrm{D}_{6}\right]\right.$ acetone, $\left.25^{\circ} \mathrm{C}\right): \delta=9.39$ (bs, 3 $\mathrm{H}$; $-\mathrm{N}=\mathrm{CH}-$ ), 8.42 (d, $J=8.9 \mathrm{~Hz}, 3 \mathrm{H}$; $\mathrm{H}_{\text {Aryl }}$ ), 7.85 (dd, $J=8.9,2.4 \mathrm{~Hz}, 3 \mathrm{H}$; $\mathrm{H}_{\text {Aryl }}$ ), 6.99 (bs, $3 \mathrm{H}$; $\mathrm{H}_{\text {Aryl }}$ ), 4.19 (m, $6 \mathrm{H}$; -O- $\mathrm{CH}_{2}-$ ), 3.75 (bd, $\left.J=9.9 \mathrm{~Hz}, 3 \mathrm{H} ;-\mathrm{CH}_{2}-\mathrm{N}=\right), 3.55$ (bd, $J=9.9 \mathrm{~Hz}, 3 \mathrm{H}$; $\left.-\mathrm{CH}_{2}-\mathrm{N}=\right), 3.25\left(\mathrm{~m}, 12 \mathrm{H} ; \mathrm{N}-\mathrm{CH}_{2}\right.$ and $\left.-\mathrm{CH}_{2}-\mathrm{SCN}\right), 1.91\left(\mathrm{~m}, 12 \mathrm{H} ;-\mathrm{CH}_{2}-\mathrm{CH}_{2}-\right)$ ppm. $-{ }^{13} \mathrm{C}$ NMR $\left(100.6 \mathrm{MHz},\left[\mathrm{D}_{6}\right]\right.$ acetone, $\left.25^{\circ} \mathrm{C}\right): \delta=170.4\left(\mathrm{C}_{\text {Aryl }}\right)$, $158.8\left(\mathrm{C}_{\text {Aryl }}\right), 150.4(-\mathrm{C}=\mathrm{N}-), 144.1\left(\mathrm{C}_{\text {Aryl }}\right), 129.7\left(\mathrm{C}_{\text {Aryl }}\right)$, $121.6\left(\mathrm{C}_{\text {Aryl }}\right), 111.9(-\mathrm{SCN}), 68.3\left(\mathrm{O}-\mathrm{CH}_{2}-\right), 58.4\left(\mathrm{CH}_{2}-\right.$ $\mathrm{SCN}), 54.1\left(-\mathrm{CH}_{2}-\mathrm{N}=\right), 33.1\left(\mathrm{~N}-\mathrm{CH}_{2}\right), 26.7\left(-\mathrm{CH}_{2}-\mathrm{CH}_{2}-\right)$, $26.3\left(-\mathrm{CH}_{2}-\mathrm{CH}_{2}-\right)$ ppm. $-\mathrm{C}_{39} \mathrm{H}_{48} \mathrm{FeN}_{10} \mathrm{O}_{3} \mathrm{~S}_{3} \mathrm{~B}_{2} \mathrm{~F}_{8} \cdot 2 \mathrm{MeOH}$ (1094.59): calcd. C 44.99, H 5.16, N 12.80, S 8.79; found C $45.28, \mathrm{H}$ 4.71, N 12.62, S 8.54. - HRMS ((+)-ESI): $m / z=428.1208$ (calcd. 428.1206 for $\mathrm{C}_{39} \mathrm{H}_{48} \mathrm{FeN}_{10} \mathrm{O}_{3} \mathrm{~S}_{3}$, $\left.[\mathrm{M}]^{2+}\right) .-$ IR $(\mathrm{KBr}): v=3436(\mathrm{~m}), 3263(\mathrm{w}), 3078(\mathrm{w}), 2923$ (s), $2853(\mathrm{~s}), 2152(\mathrm{~s}), 1613(\mathrm{~m}), 1593(\mathrm{~s}), 1561(\mathrm{~s}), 1593(\mathrm{~s})$, $1661(\mathrm{~m}), 1495(\mathrm{~m}), 1472(\mathrm{~m}), 1379(\mathrm{~m}), 1309(\mathrm{~m}), 1280(\mathrm{~s})$, 1233 (s), 1054 (s), 893 (m), 837 (m), 762 (w), 742 (w), 660 (w), $642(\mathrm{w}), 621(\mathrm{w}), 565(\mathrm{w}), 519(\mathrm{~m}), 471(\mathrm{w}), 409(\mathrm{w})$ $\mathrm{cm}^{-1}$.

Synthesis of tris[2-(\{[5-(4-thiocyanatobutoxy)pyridin-2-yl$\kappa N$ ]methylene (amino- $\kappa N)$-ethyl]amine /zinc(II) perchlorate $\left(6^{\mathrm{Zn}}\right)$

Tris-(2-aminoethyl)amine, 'tren', (4; $20 \mathrm{mg}, 0.14 \mathrm{mmol})$ was dissolved in ethanol $(2 \mathrm{~mL})$ and the solution added to a solution of 5-(4-thiocyanatobutoxy)pyridine-2carbaldehyde $(3 ; 99 \mathrm{mg}, 0.42 \mathrm{mmol})$ in ethanol $(3 \mathrm{~mL})$. The resulting solution was stirred at room temperature for $1 \mathrm{~h}$, before adding dropwise a solution of $\mathrm{Zn}\left(\mathrm{ClO}_{4}\right)_{2} \cdot 6 \mathrm{H}_{2} \mathrm{O}$ $(52 \mathrm{mg}, 0.14 \mathrm{mmol})$ in ethanol $(2 \mathrm{~mL})$. The resulting colourless suspension was stirred at room temperature for $12 \mathrm{~h}$ and filtered, the remaining colourless solid washed with dry diethyl ether $(5 \mathrm{~mL})$ and dried in vacuo $(100 \mathrm{mg}, 65 \%) .-{ }^{1} \mathrm{H}$ NMR $\left(400 \mathrm{MHz},\left[\mathrm{D}_{7}\right]\right.$ dimethyl formamide, $\left.25^{\circ} \mathrm{C}\right): \delta=8.90$ (bs, $3 \mathrm{H}$; - $\mathrm{N}=\mathrm{CH}-$ ), 8.20 (d, $J=8.7 \mathrm{~Hz}, 3 \mathrm{H}$; $\mathrm{H}_{\text {Aryl }}$ ), 7.97 $\left(\mathrm{dd}, J=8.7,2.8 \mathrm{~Hz}, 3 \mathrm{H} ; \mathrm{H}_{\text {Aryl }}\right), 7.20(\mathrm{~d}, J=2.8 \mathrm{~Hz}, 3 \mathrm{H}$; $\left.\mathrm{H}_{\text {Aryl }}\right), 4.19\left(\mathrm{~m}, 6 \mathrm{H}\right.$; -O- $\left.\mathrm{CH}_{2}-\right), 3.86\left(\mathrm{~m}, 3 \mathrm{H} ;-\mathrm{CH}_{2}-\mathrm{N}=\right)$, $3.60\left(\mathrm{~m}, 3 \mathrm{H} ;-\mathrm{CH}_{2}-\mathrm{N}=\right), 3.20\left(\mathrm{~m}, 9 \mathrm{H} ; \mathrm{N}-\mathrm{CH}_{2}\right.$ and $\left.-\mathrm{CH}_{2}-\mathrm{SCN}\right), 3.03\left(\mathrm{~m}, 3 \mathrm{H}, \mathrm{N}-\mathrm{CH}_{2}\right), 1.89\left(\mathrm{~m}, 12 \mathrm{H}\right.$; $\left.-\mathrm{CH}_{2}-\right)$ ppm. - $\mathrm{C}_{39} \mathrm{H}_{48} \mathrm{ZnN}_{10} \mathrm{O}_{11} \mathrm{~S}_{3} \cdot \mathrm{EtOH}$ (1108.18): calcd. C 44.31, H 4.90, N 12.60, S 8.66; found C 44.46, H 4.58, N 12.46, S 8.44. - MS ((+)-ESI): $m / z=432.12$ (calcd. 432.12 for $\left.\mathrm{C}_{39} \mathrm{H}_{48} \mathrm{ZnN}_{10} \mathrm{O}_{3} \mathrm{~S}_{3},[\mathrm{M}]^{2+}\right)$. - IR (KBr): $v=3499(\mathrm{~m})$, 
Table 3. Crystal structure data for $\mathbf{6}^{\mathrm{Fe}} \cdot 1 / 4 \mathrm{Et}_{2} \mathrm{O}$ and $7 \cdot \mathrm{CH}_{3} \mathrm{CN}$.

\begin{tabular}{|c|c|c|}
\hline & $6^{\mathrm{Fe}} \cdot 1 / 4 \mathrm{Et}_{2} \mathrm{O}$ & $7 \cdot \mathrm{CH}_{3} \mathrm{CN}$ \\
\hline Empirical formula & $\mathrm{C}_{40} \mathrm{H}_{50.50} \mathrm{~B}_{2} \mathrm{~F}_{8} \mathrm{FeN}_{10} \mathrm{O}_{3.25} \mathrm{~S}_{3}$ & $\mathrm{C}_{38} \mathrm{H}_{48} \mathrm{~B}_{2} \mathrm{~F}_{8} \mathrm{FeN}_{13} \mathrm{O}_{3} \mathrm{PS}_{4}$ \\
\hline$M_{\mathrm{r}}$ & 1049.05 & 1123.57 \\
\hline Crystal size, $\mathrm{mm}^{3}$ & $0.071 \times 0.139 \times 0.220$ & $0.20 \times 0.14 \times 0.01$ \\
\hline Crystal system & monoclinic & triclinic \\
\hline Space group & $P 2_{1} / c$ & $P^{\overline{1}}$ \\
\hline$a, \AA$ & $17.7149(13)$ & $12.2417(7)$ \\
\hline$b, \AA$ & $19.3445(16)$ & $12.4229(8)$ \\
\hline$c, \AA$ & $14.2442(11)$ & 17.3521(9) \\
\hline$\alpha, \operatorname{deg}$ & 90 & $72.654(5)$ \\
\hline$\beta, \operatorname{deg}$ & $103.288(8)$ & $75.440(5)$ \\
\hline$\gamma$, deg & 90 & $84.078(5)$ \\
\hline$V, \AA^{3}$ & $4750.6(7)$ & $2436.8(2)$ \\
\hline$Z$ & 4 & 2 \\
\hline$D_{\text {calcd. }}, \mathrm{g} \mathrm{cm}^{-3}$ & 1.47 & 1.53 \\
\hline$\mu, \mathrm{cm}^{-1}$ & 4.5 & 0.6 \\
\hline$F(000), e$ & 2170 & 1156 \\
\hline \multirow[t]{3}{*}{$h k l$ range } & $-21 \leq h \leq+19$ & $-14 \leq h \leq+15$ \\
\hline & $-23 \leq k \leq+22$ & $-15 \leq k \leq+15$ \\
\hline & $-12 \leq l \leq+17$ & $-19 \leq l \leq+21$ \\
\hline $\sin \theta] / \lambda)_{\max }, \AA^{-1}$ & 0.599 & 0.617 \\
\hline Refl. measured & 19133 & 19474 \\
\hline Refl. unique / $R_{\text {int }}$ & $8557 / 0.0862$ & $9570 / 0.0957$ \\
\hline Refl. observed / $R_{\sigma}^{\mathrm{a}}$ & $4385 / 0.1084$ & $3700 / 0.2735$ \\
\hline Param. refined/restr. & $587 / 112$ & $782 / 303$ \\
\hline$u^{\mathrm{b}}$ & 0.1951 & 0.0350 \\
\hline$R_{1} / w R_{2}^{\mathrm{b}}$ (obs. refl.) $)^{\mathrm{a}}$ & $0.1006 / 0.2753$ & $0.0657 / 0.0980$ \\
\hline$R_{1} / w R_{2}^{\mathrm{b}}$ (all refl.) & $0.1653 / 0.3450$ & $0.1884 / 0.1119$ \\
\hline$S / S^{\prime}$ & $1.026 / 1.027$ & $0.817 / 0.834$ \\
\hline$\Delta \rho_{\text {fin }}(\max / \min ), e \AA^{-3}$ & $-1.27 / 0.61$ & $-0.46 / 0.50$ \\
\hline
\end{tabular}

${ }^{\mathrm{a}} I>2 \sigma(I) ;{ }^{\mathrm{b}} R_{1}=\Sigma|| F_{\mathrm{o}}|-| F_{\mathrm{c}}|| / \Sigma\left|F_{\mathrm{o}}\right|, w R_{2}=\left[\Sigma w\left(F_{\mathrm{o}}^{2}-F_{\mathrm{c}}^{2}\right)^{2} / \Sigma w F_{\mathrm{o}}^{4}\right]^{1 / 2}, w=\left[\sigma^{2}\left(F_{\mathrm{o}}^{2}\right)+(u P)^{2}\right]^{-1}$ with $P=\left[\max \left(F_{\mathrm{o}}^{2}, 0\right)+2 F_{\mathrm{c}}^{2}\right] / 3$.

$3098(\mathrm{w}), 3000$ (s), 2963 (s), 2552 (w),2142(s) 1652 (s), 1561 (s), 1490 (w), 1453 (m), 1350 (m), 1330 (m), 1290 (m), $1210(\mathrm{~m}), 1120(\mathrm{~m}), 1085$ (s), $850(\mathrm{~m}), 790(\mathrm{~m}), 650$ (w), $10637(\mathrm{w}), 623(\mathrm{~m}), 550(\mathrm{w}), 490(\mathrm{w}), 488(\mathrm{w}) \mathrm{cm}^{-1}$.

Synthesis of [tris(1-methyl-2-\{[5-(4-thiocyanatobutoxy)-

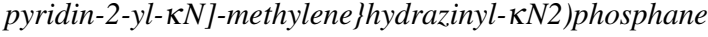
sulphide]iron(II) tetrafluoroborate (7)

$1,1^{\prime}, 1^{\prime \prime}$-Trimethyl(thiophosphoryl)trihydrazide $\quad(\mathbf{5} ; 15.9$ $\mathrm{mg}, \quad 0.08 \mathrm{mmol}$ ) was dissolved in ethanol (degassed with nitrogen, $2 \mathrm{~mL})$, and a solution of 5-(4thiocyanatobutoxy)pyridine-2-carbaldehyde $(3 ; 58.0 \mathrm{mg}$, $0.25 \mathrm{mmol})$ in ethanol $(2 \mathrm{~mL})$ added dropwise. The resulting solution was stirred at room temperature for $1 \mathrm{~h}$, and then a solution of $\mathrm{Fe}\left(\mathrm{BF}_{4}\right)_{2} \cdot 6 \mathrm{H}_{2} \mathrm{O}(27.0 \mathrm{mg}, 0.08 \mathrm{mmol})$ in ethanol (degassed, $1 \mathrm{~mL}$ ) was added dropwise. The resulting dark-red suspension was stirred at room temperature for $12 \mathrm{~h}$, filtered, the remaining red solid washed with dry diethyl ether $(5 \mathrm{~mL})$, and dried in vacuo $(70 \mathrm{mg}, 80 \%)$. Single crystals suitable for X-ray diffraction were obtained from acetonitrile solution at $3^{\circ} \mathrm{C}$ by isothermal diffusion of diethyl ether. $-{ }^{1} \mathrm{H}$ NMR $\left(200 \mathrm{MHz},\left[\mathrm{D}_{3}\right.\right.$ ]acetonitrile, $\left.25^{\circ} \mathrm{C}\right): \delta=8.54$ (d, $J=3.025 \mathrm{~Hz}, 3 \mathrm{H} ;-\mathrm{N}=\mathrm{CH}-), 8.09$ (d, $J=9.1 \mathrm{~Hz}, 3$ $\left.\mathrm{H} ; \mathrm{H}_{\text {Aryl }}\right), 7.66$ (dd, $\left.J=9.1,2.7 \mathrm{~Hz}, 3 \mathrm{H} ; \mathrm{H}_{\text {Aryl }}\right), 6.23$ (d, $\left.J=2.7 \mathrm{~Hz}, 3 \mathrm{H} ; \mathrm{H}_{\text {Aryl }}\right), 4.03\left(\mathrm{t}, J=5.8 \mathrm{~Hz}, 6 \mathrm{H} ; \mathrm{O}_{-} \mathrm{CH}_{2}-\right.$ ), $3.42\left(\mathrm{~d}, J=12.1 \mathrm{~Hz}, 9 \mathrm{H} ; \mathrm{N}-\mathrm{CH}_{3}\right), 3.01(\mathrm{t}, J=6.7 \mathrm{~Hz}, 6$ $\mathrm{H} ; \mathrm{CH}_{2}-\mathrm{SCN}$ ), 1.85 (m, $12 \mathrm{H}$; $\left.-\mathrm{CH}_{2}-\mathrm{CH}_{2}-\right)$ ppm. $-{ }^{31} \mathrm{P}$ NMR $\left(162 \mathrm{MHz},\left[\mathrm{D}_{3}\right]\right.$ acetonitrile, $\left.25^{\circ} \mathrm{C}\right): \delta=66.9(\mathrm{~s}, 1 \mathrm{P})$ $30 \mathrm{ppm} .-{ }^{13} \mathrm{C}$ NMR $\left(100.6 \mathrm{MHz},\left[\mathrm{D}_{3}\right]\right.$ acetonitrile, $\left.25^{\circ} \mathrm{C}\right)$ : $\delta=157.9\left(\mathrm{C}_{\text {Aryl }}\right), 151.0(\mathrm{~d}, J(\mathrm{C}, \mathrm{P})=8.7 \mathrm{~Hz} ;-\mathrm{C}=\mathrm{N}-), 150.7$ $\left(\mathrm{C}_{\text {Aryl }}\right) 144.3\left(\mathrm{C}_{\text {Aryl }}\right), 129.7\left(\mathrm{C}_{\text {Aryl }}\right), 123.9\left(\mathrm{C}_{\text {Aryl }}\right), 113.5$ $(\mathrm{SCN}), 69.6\left(\mathrm{O}-\mathrm{CH}_{2}-\right), 38.0\left(\mathrm{~d}, J(\mathrm{C}, \mathrm{P})=3.23 \mathrm{~Hz} ; \mathrm{N}-\mathrm{CH}_{3}\right)$, $34.1\left(\mathrm{CH}_{2}-\mathrm{SCN}\right), 27.5\left(-\mathrm{CH}_{2}-\mathrm{CH}_{2}-\right), 27.1\left(-\mathrm{CH}_{2}-\mathrm{CH}_{2}-\right)$ ppm. $-\mathrm{C}_{36} \mathrm{H}_{45} \mathrm{FeN}_{12} \mathrm{O}_{3} \mathrm{PS}_{4} \mathrm{~B}_{2} \mathrm{~F}_{8} \cdot \mathrm{EtOH}$ (1128.59): calcd. C 40.44, H 4.55, N 14.89, S 11.36; found C 41.18, H 3.99, N 14.92, S 11.59. - HRMS ((+)-ESI): $m / z=454.0841$ (calcd. 454.0848 for $\left.\mathrm{C}_{36} \mathrm{H}_{45} \mathrm{FeN}_{12} \mathrm{O}_{3} \mathrm{PS}_{4},[\mathrm{M}]^{2+}\right)$. - IR (KBr): $v=3421(\mathrm{~m}), 2921(\mathrm{~m}), 2150(\mathrm{~s}), 1576(\mathrm{~s}), 1459(\mathrm{~m}), 1368$ 
(w), $1310(\mathrm{~m}), 1272,(\mathrm{~m}), 1235$ (s), 1081 (s), 1033 (s), 948 (m), $890(\mathrm{~m}), 842(\mathrm{w}), 788(\mathrm{~m}), 740(\mathrm{w}), 698(\mathrm{w}), 655(\mathrm{w})$, $613(w), 559(w), 522(w), 464(w) \mathrm{cm}^{-1}$.

\section{X-Ray structure determination}

For $7 \cdot \mathrm{CH}_{3} \mathrm{CN}$, data were collected at $150.0(1) \mathrm{K}$ using an Oxford Diffraction Xcalibur S diffractometer equipped with a goniometer in $\kappa$ geometry, a Sapphire 3 CCD detector, and a graphite-monochromated Enhance $\mathrm{MoK}_{\alpha}$ source $(\lambda=0.71073 \AA)$. For $\mathbf{6}^{\mathrm{Fe}} \cdot 1 / 4 \mathrm{Et}_{2} \mathrm{O}$, an Agilent Nova diffractometer equipped with a goniometer in $\kappa$ geometry, an Atlas CCD detector, and a mirror-monochromated "SuperNova" $\mathrm{CuK}_{\alpha}$ source $(\lambda=1.54184 \AA)$ was used. Diffraction images were integrated with CRYSALISPRO [78]. An empirical absorption correction using spherical harmonics implemented in the SCALE3 ABSPACK scaling algorithm was performed [78]. Structures were solved with SHELXS-2014 using Direct Methods and refined with SHELXL-2014 against $F_{\mathrm{o}}^{2}$ data using the full-matrix least-squares algorithm [79]. Non-hydrogen atoms were refined anisotropically; hydrogen atoms were refined isotropically with standard riding models. Molecular graphics were produced using MERCURY [80]. Crystallographic details are summarised in Table 3.

In $6^{\mathrm{Fe}} \cdot 1 / 4 \mathrm{Et}_{2} \mathrm{O}$, two 4-thiocyanatobutyl residues exhibit strong positional disorder. We were able to model one of them (C41-N46) in two discrete positions using same-distance and -angle as well as tight rigid-bond and isotropy restraints. Occupancies refined to $0.61(2) / 0.39(2)$. The second one (with tentative atom names C61-N67), along with one molecule of diethyl ether per unit cell, was not amenable to any discrete model but had to be treated as a diffuse contribution to the overall scattering without specific atom positions, using the routine SQUEEZE as incorporated in PLATON $[80,81]$. In $7 \cdot \mathrm{CH}_{3} \mathrm{CN}$, one tetrafluoroborate ion (B80-F84) and two 4-thiocyanatobutyl residues (C21N27, C43-N47) exhibit strong rotational/positional disorder. Each of them was modelled in two discrete positions using same-distance and -angle as well as tight rigid-bond and isotropy restraints. Occupancies refined to $0.69(2) / 0.31(2)$, $0.375(8) / 0.625(8)$, and $0.52(2) / 0.48(2)$, respectively.

CCDC 1012304-1012305 contain the supplementary crystallographic data for this paper. These data can be obtained free of charge from The Cambridge Crystallographic Data Centre via http://www.ccdc.cam.ac.uk/data_request/cif.

\section{Supporting information}

NMR spectra of compounds $\mathbf{3}, \mathbf{6}^{\mathrm{Fe}}$, and $7\left({ }^{1} \mathrm{H},{ }^{13} \mathrm{C}\right.$; also ${ }^{31} \mathrm{P}$ for 7$)$; $T$-dependent magnetic susceptibility of compounds 6 and 7; $T$-dependent ${ }^{1} \mathrm{H}$ NMR spectra of $\mathbf{6}^{\mathrm{Fe}}$ and $\mathbf{6}^{\mathbf{Z n}}$; STM images of assembled films; UV/Vis spectra and IRRAS spectrum of compound $\mathbf{7}$ on gold; molecular structure, IRRAS and additional XPS spectra of $6^{\mathbf{F e}}$ and the reference compound as Supporting Information (12 pages) which can be accessed under DOI: 10.5560/ZNB.2014-4159.

\section{Acknowledgement}

Support of this work by the Deutsche Forschungsgemeinschaft (SFB 658, "Elementary processes in molecular switches on surfaces") is gratefully acknowledged. We thank Professor Dr. Paul Müller and Dr. Klaus Gieb (FriedrichAlexander-Universität Erlangen-Nürnberg) for the SQUID measurement of compound $\mathbf{6}^{\mathrm{Fe}}$ and Dipl.-Chem. Nicole Spintig (Technische Universität Berlin) for providing a crystalline sample of compound $\mathbf{6}^{\mathrm{Fe}}$.
[1] A. Ulman, Chem. Rev. 1996, 96, 1533 - 1554.

[2] J. C. Love, L. A. Estroff, J. K. Kriebel, R. G. Nuzzo, G. M. Whitesides, Chem. Rev. 2005, 105, 1103-1169.

[3] M. Kind, C. Wöll, Prog. Surf. Sci. 2009, 84, $230-$ 278.

[4] F. Schreiber, J. Phys.: Condens. Matter 2004, 16, R881 - R900.

[5] J. J. Gooding, S. Ciampi, Chem. Soc. Rev. 2011, 40, $2704-2718$

[6] E. Pensa, E. Cortes, G. Corthey, P. Carro, C. Vericat, M. H. Fonticelli, G. Benitez, A. A. Rubert, R. C. Salvarezza, Acc. Chem. Res. 2012, 45, 1183-1192.

[7] H. Hakkinen, Nat. Chem. 2012, 4, 443 - 455.

[8] C. Shen, M. Haryono, A. Grohmann, M. Buck, T. Weidner, N. Ballav, M. Zharnikov, Langmuir 2008, 24, $12883-12891$
[9] U. Jung, C. Schütt, O. Filinova, J. Kubitschke, R. Herges, O. Magnussen, J. Phys. Chem. C 2012, 116, $25943-25948$

[10] C. C. Clark, G. J. Meyer, Q. Wei, E. Galoppini, J. Phys. Chem. B 2006, 110, 11044-11046.

[11] E. K. Beloglazkina, A. G. Majouga, R. B. Romashkina, N. V. Zyk, N. S. Zefirov, Russ. Chem. Rev. 2012, 81, 65-90.

[12] P. Gütlich, H. A. Goodwin, Top. Curr. Chem. 2004, $233,1-48$

[13] J. Klingele, D. Kaase, M. Schmucker, Y. Lan, G. Chastanet, J.-F. Létard, Inorg. Chem. 2013, 52, 6000-6010.

[14] M. Cavallini, I. Bergenti, S. Milita, G. Ruani, I. Salitros, Z.-R. Qu, R. Chandrasekar, M. Ruben, Angew. Chem. Int. Ed. 2008, 47, 8596-8600. 
[15] M. Cavallini, Phys. Chem. Chem. Phys. 2012, 14, $11867-11876$

[16] A. Grohmann, M. Haryono, K. Student, P. Müller, M. Stocker, Eur. J. Inorg. Chem. 2013, 5-6, 662-669.

[17] M. Bernien, D. Wiedemann, C. F. Hermanns, A. Krüger, D. Rolf, W. Kroener, P. Müller, A. Grohmann, W. Kuch, J. Phys. Chem. Lett. 2012, 3, $3431-$ 3434.

[18] B. Warner, J. C. Oberg, T. G. Gill, F. El Hallak, C. F. Hirjibehedin, M. Serri, S. Heutz, M.-A. Arrio, P. Sainctavit, M. Mannini, G. Poneti, R. Sessoli, P. Rosa, J. Phys. Chem. Lett. 2013, 4, 1546-1552.

[19] T. G. Gopakumar, F. Matino, F. Tuczek, R. Berndt, H. Naggert, A. Bannwarth, Angew. Chem. Int. Ed. 2012, $51,6262-6266$.

[20] T. Miyamachi, M. Gruber, V. Davesne, M. Bowen, S. Boukari, L. Joly, F. Scheurer, G. Rogez, T. K. Yamada, P. Ohresser, E. Beaurepaire, W. Wulfhekel, Nat. Commun. 2012, 3, 938.

[21] T. G. Gopakumar, M. Bernien, H. Naggert, F. Matino, C. F. Hermanns, A. Bannwarth, S. Mühlenberend, A. Krüger, D. Krüger, F. Nickel, W. Walter, R. Berndt, W. Kuch, F. Tuczek, Chem. Eur. J. 2013, 19, $15702-15709$

[22] A. Schramm, C. Stroh, K. Dossel, M. Lukas, M. Fischer, F. Schramm, O. Fuhr, H. v. Lohneysen, M. Mayor, Eur. J. Inorg. Chem. 2013, 1, 70-79.

[23] R. Sakamoto, Y. Ohirabaru, R. Matsuoka, H. Maeda, S. Katagiri, H. Nishihara, Chem. Comm. 2013, 49, $7108-7110$.

[24] T. Kitagawa, Y. Idomoto, H. Matsubara, D. Hobara, T. Kakiuchi, T. Okazaki, K. Komatsu, J. Org. Chem. 2006, $71,1362-1369$.

[25] S. Katano, Y. Kim, H. Matsubara, T. Kitagawa, M. Kawai, J. Am. Chem. Soc. 2007, 129, 2511-2515.

[26] T. Weidner, M. Zharnikov, J. Hosbach, D. G. Castner, U. Siemeling, J. Phys. Chem. C 2010, 114, $14975-14982$.

[27] H. Jacob, K. Kathirvel, F. Petersen, T. Strunskus, A. Bannwarth, S. Meyer, F. Tuczek, Langmuir 2013, 29, $8534-8543$.

[28] S. Liatard, J. Chauvin, F. Balestro, D. Jouvenot, F. Loiseau, A. Deronzier, Langmuir 2012, 28, 1091610924.

[29] J. M. Tour, L. Jones II, D. L. Pearson, J. J. S. Lamba, T. P. Burgin, G. M. Whitesides, D. L. Allara, J. Am. Chem. Soc. 1995, 117, 9529-9534.

[30] L. Cai, Y. Yao, J. Yang, D. W. Price, Jr., J. M. Tour, Chem. Mater. 2002, 14, 2905-2909.

[31] A. Schramm, C. Stroh, K. Dossel, M. Lukas, O. Fuhr, H. v. Lohneysen, M. Mayor, Chem. Commun. 2013, 49, $1076-1078$.
[32] T. Weidner, A. Krämer, C. Bruhn, M. Zharnikov, A. Shaporenko, U. Siemeling, F. Träger, Dalton Trans. 2006, 35, 2767-2777.

[33] D. O. Bellisario, A. D. Jewell, H. L. Tierney, A. E. Baber, E. C. H. Sykes, J. Phys. Chem. C 2010, 114, $14583-14589$.

[34] J. W. Ciszek, Z. K. Keane, L. Cheng, M. P. Stewart, L. H. Yu, D. Natelson, J. M. Tour, J. Am. Chem. Soc. 2006, 128, 3179-3189.

[35] J. W. Ciszek, M. P. Stewart, J. M. Tour, J. Am. Chem. Soc. 2004, 126, $13172-13173$.

[36] Y. Choi, Y. Jeong, H. Chung, E. Ito, M. Hara, J. Noh, Langmuir 2008, 24, $91-96$.

[37] C. Shen, M. Buck, J. D. E. T. Wilton-Ely, T. Weidner, M. Zharnikov, Langmuir 2008, 24, 6609-6615.

[38] S. Y. Lee, Y. Choi, E. Ito, M. Hara, H. Lee, J. Noh, Phys. Chem. Chem. Phys. 2013, 15, 3609-3617.

[39] I. Trapp, M. Löble, J. Meyer, F. Breher, Inorg. Chim. Acta 2011, 374, 373 - 384.

[40] P. Stock, T. Pędziński, N. Spintig, A. Grohmann, G. Hörner, Chem. Eur. J. 2013, 19, 839-842.

[41] M. A. Hoselton, L. J. Wilson, R. S. Drago, J. Am. Chem. Soc. 1975, 97, 1722-1729.

[42] M. Seredyuk, A. B. Gaspar, V. Ksenofontov, Y. Galyametdinov, J. Kusz, P. Gütlich, J. Am. Chem. Soc. 2008, 130, $1431-1439$.

[43] G. Hörner, P. Stock, P. Müller, K. Gieb, C. Oelsner, D. M. Guldi, A. Grohmann, unpublished results.

[44] A. Bousseksou, G. Molnar, L. Salmon, W. Nicolazzi, Chem. Soc. Rev. 2011, 40, 3313-3335.

[45] C. D. Bain, E. B. Troughton, Y. T. Tao, J. Evall, G. M. Whitesides, R. G. Nuzzo, J. Am. Chem. Soc. 1989, 111, $321-335$.

[46] Y. Chen, A. Erbe, Surf. Sci. 2013, 607, 39-46.

[47] M. S. Alam, M. Stocker, K. Gieb, P. Müller, M. Haryono, K. Student, A. Grohmann, Angew. Chem. Int. Ed. 2010, 49, 1159-1163.

[48] D. Landoldt, Corrosion and surface chemistry of Metals, EPFL Press, Lausanne, 2003.

[49] M. Khalil, M. A. Marcus, A. L. Smeigh, J. K. McCusker, H. H. W. Chong, R. W. Schoenlein, J. Phys. Chem. A 2006, 110, $38-44$.

[50] A. Erbe, http://home.arcor.de/aerbe/en/prog/a/reflcalc. html, 2013.

[51] J. Lekner, Theory of Reflection of Electromagnetic and Particle Waves, M. Nijhoff Publishers, Dordrecht, 1987.

[52] P. G. Etchegoin, E. C. Le Ru, M. Meyer, J. Chem. Phys. 2006, 125, $164705-164708$.

[53] U. Fano, Phys. Rev. 1961, 124, $1866-1878$.

[54] M. K. Debe, Prog. Surf. Sci. 1987, 24, 1-282.

[55] J. W. Ciszek, J. M. Tour, Chem. Mater. 2005, 17, $5684-5690$. 
[56] K. Heister, M. Zharnikov, M. Gunze, L. S. O. Johansson, A. Ulman, Langmuir 2001, 17, 8-11.

[57] T. Ishida, M. Hara, I. Kojima, S. Tsuneda, N. Nishida, H. Sasabe, W. Knoll, Langmuir 1998, 14, $2092-2096$.

[58] P. Cyganik, M. Buck, T. Strunskus, A. Shaporenko, G. Witte, M. Zharnikov, C. Wöll, J. Phys. Chem. C 2007, $111,16909-16919$.

[59] M. Himmelhaus, I. Gauss, M. Buck, F. Eisert, C. Wöll, M. Grunze, J. Electron. Spectrosc. Relat. Phenom. 1998, 92, 139- 149 .

[60] T. Weidner, N. Ballav, U. Siemeling, D. Troegel, T. Walther, R. Tacke, D. G. Castner, M. Zharnikov, J. Phys. Chem. C 2009, 113, 19609-19617.

[61] T. Ishida, N. Choi, W. Mizutani, H. Tokumoto, I. Kojima, H. Azehara, H. Hokari, U. Akiba, M. Fujihira, Langmuir 1999, 15, 6799-6806.

[62] Y. W. Yang, L. J. Fan, Langmuir 2002, 18, 1157-1164.

[63] P. Brant, L. S. Benner, A. L. Balch, Inorg. Chem. 1979, $18,3422-3427$.

[64] M. Mullet, V. Khare, C. Ruby, Surf. Interface Anal. 2008, 40, 323-328

[65] C. Isvoranu, B. Wang, K. Schulte, E. Ataman, J. Knudsen, J. N. Andersen, M. L. Bocquet, J. Schnadt, J. Phys. Cond. Matter 2010, 22, 472002.

[66] M. Schmid, J. Zirzlmeier, H.-P. Steinrück, J. M. Gottfried, J. Phys. Chem. C 2011, 115, 17028-17035.

[67] Y. Zubavichus, M. Zharnikov, Y. Yang, O. Fuchs, E. Umbach, C. Heske, A. Ulman, M. Grunze, Langmuir 2004, 20, $11022-11029$.

[68] C. Silien, M. Buck, G. Goretzki, D. Lahaye, N. R. Champness, T. Weidner, M. Zharnikov, Langmuir 2009, 25, 959-967.
[69] G. P. Lopez, D. G. Castner, B. D. Ratner, Surf. Interface Anal. 1991, 17, $267-272$

[70] P. E. Laibinis, C. D. Bain, R. G. Nuzzo, G. M. Whitesides, J. Phys. Chem. 1995, 99, 7663 - 7676.

[71] P. Boulanger, J. Riga, J. Delhalle, J. J. Verbist, Polymer 1988, 29, $797-801$.

[72] J. P. Majoral, R. Kraemer, J. Navech, F. Mathis, Tetrahedron 1976, 32, 2633-2644.

[73] R. Adams, D. C. Blomstrom, J. Am. Chem. Soc. 1953, $75,2375-2377$

[74] M. H. Dishner, M. M. Ivey, S. Gorer, J. C. Hemminger, F. J. Feher, J. Vac. Sci. Technol. A 1998, 16, $3295-3301$

[75] H. Fujiwara in Spectroscopic Ellipsometry: Principles and Applications, John Wiley \& Sons, Chichester, 2007.

[76] R. M. A. Azzam, N. M. Bashara, Ellipsometry and Polarised Light, Elsevier Science, Amsterdam, 1999.

[77] CRYsAlisPro Software System, Intelligent Data Collection and Processing Software for Small Molecule and Protein Crystallography, Agilent Technologies Ltd., Yarnton, Oxfordshire (U. K.) 2013.

[78] G. M. Sheldrick, Acta Crystallogr. 2008, A64, 112 122.

[79] C. F. Macrae, I. J. Bruno, J. A. Chisholm, P. R. Edgington, P. McCabe, E. Pidcock, L. Rodriguez-Monge, R. Taylor, J. van de Streek, P. A. Wood, J. Appl. Crystallogr. 2008, 41, 466-470.

[80] P. van der Sluis, A. L. Spek, Acta Crystallogr. 1990, A46, 194-201.

[81] A. L. Spek, Acta Crystallogr. 2009, D65, 148-155. 